\title{
COOPERATIVE MEASUREMENTS OF RADIO FADING IN 1925
}

\author{
By J. H. Dellinger, C. B. Jolliffe, and T. Parkinson
}

\section{ABSTRACT}

At the beginning of 1925 the bureau invited a number of laboratories to participate in the beginning of a cooperative program of measurement. During the year the work was largely confined to measurements of fading at frequencies within the broadcast band. The general plan of the work was the arrangement of special transmissions in which a station transmitted continuously during a specified period while the observing laboratories made graphic records simultaneously. The observing method was that of Pickard, described in his paper, "Short-period variations in radio reception," published in the Proceedings of the Institute of Radio Engineers, volume 12, page 119, 1924. Twenty-three laboratories engaged in this work.

The series of measurements on fading were devoted to studies of fading effects during the sunset period, effects during the solar eclipse of January 24, the fading variations throughout a 24-hour day, and the effects of high transmitting power on fading. For these tests special transmissions were made by broadcasting stations WGY and KDKA.

The results of 150 graphic fading records made by the cooperating observers established definitely a number of facts about fading that had been only surmised or guessed previously. In addition, a number of new facts about fading and other vagaries of radio waves were brought to light. Fading is at its worst about 60 to 125 miles from a broadcasting station; for greater distances it diminishes, but then increases again with distance, and has repeated maxima and minima for greater distances. There are two readily distinguishable kinds of fading, a fairly slow and a relatively rapid fluctuation.

This work led to the discovery of a highly regular kind of fading which sometimes occurs during the 45 minutes just following sunset. This is evidently due to an interference phenomenon, and its period shows a correlation with the distance between the transmitting and receiving points.

\section{CONTENTS}

I. Introduction

II. Status of knowledge of fading.

III. Apparatus and methods of measurement. .

IV. Radio phenomena during solar eclipse._.

V. Sunset fading tests_.

VI. Special periodic type of fading _. 437

VII. Twenty-four-hour fading test_....... 440

VIII. Effect of high power on fading .

IX. Intensity and fluctuation as functions of distance........ 443

X. Conclusions..... 447

XI. Acknowledgments._. 449 


\section{INTRODUCTION}

This is the third extensive program of cooperative radio-wavephenomena observations conducted by the Bureau of Standards at frequencies within and above the broadcast range. The first two of these were qualitative investigations carried on with the cooperation of several hundred amateurs in 1920-21 ${ }^{1}$ and 1922-1924, ${ }^{2}$ being, respectively, on radio-signal fading and on the conditions affecting distance range of broadcasting. In 1924 methods came into rather general use for making quantitative measurements of the various transmission phenomena. At the beginning of 1925 the bureau invited a number of laboratories to participate in the beginning of a cooperative program of measurements.

The several quantities meriting cooperative study on a large scale include: Field intensity, fading, direction variations, polarization, and atmospherics. In 1925 the work was largely confined to measurements of fading. This quantity was selected because fading phenomena give a particularly promising means of studying the wave characteristics, and also because the apparatus required is relatively simple. The work was mainly at the broadcast frequencies, because transmissions with uninterrupted carrier wave are not so commonly available in other parts of the frequency spectrum. Results at other than broadcast frequencies and direction observations, where mentioned herein, are therefore considered as incidental to the principal aim of the 1925 work, which was the study of fading phenomena in the broadcast range.

The work was done by the aid of special transmissions from a broadcasting station during which the observing laboratories made graphic records. The observing method was that described by Pickard. ${ }^{3}$ Mr. Pickard participated in the 1925 program and placed his experience and skill fully at the disposal of the bureau and other cooperators.

Twenty-three laboratories were engaged in this work. Their names are listed at the end of this paper. Figure 1 shows the geographical distribution. About 20 other laboratories expressed interest in the work and made some effort to begin observations, but the ones listed are the only ones that completed observations and sent them in. The results of some of the tests have been described in part in special reports that some of the cooperating observers have published. A preliminary paper on the work as a whole was pre-

1 B. S. Sci. Paper No. 476, Radio Signal Fading Phenomena. J. H. Dellinger and L. E. Whittemore, J. Wash. Acad. Sci., 11, p. 245; 1921.

B. S. Tech. Paper No. 297, A Statistical Study of Conditions Affecting the Distance Range of Radio Telephone Broadcasting Stations, O. M. Jansky, jr.

" "Short-period variations in radio reception," G. W. Pickard, Proc. I. R. E., 12, p. 119; 1924. 
sented by the present authors before the April 24, 1926, meeting of the American section, International Union of Scientific Radio Telegraphy, and an abstract was published in Radio News, 8, p. 146; August, 1926.

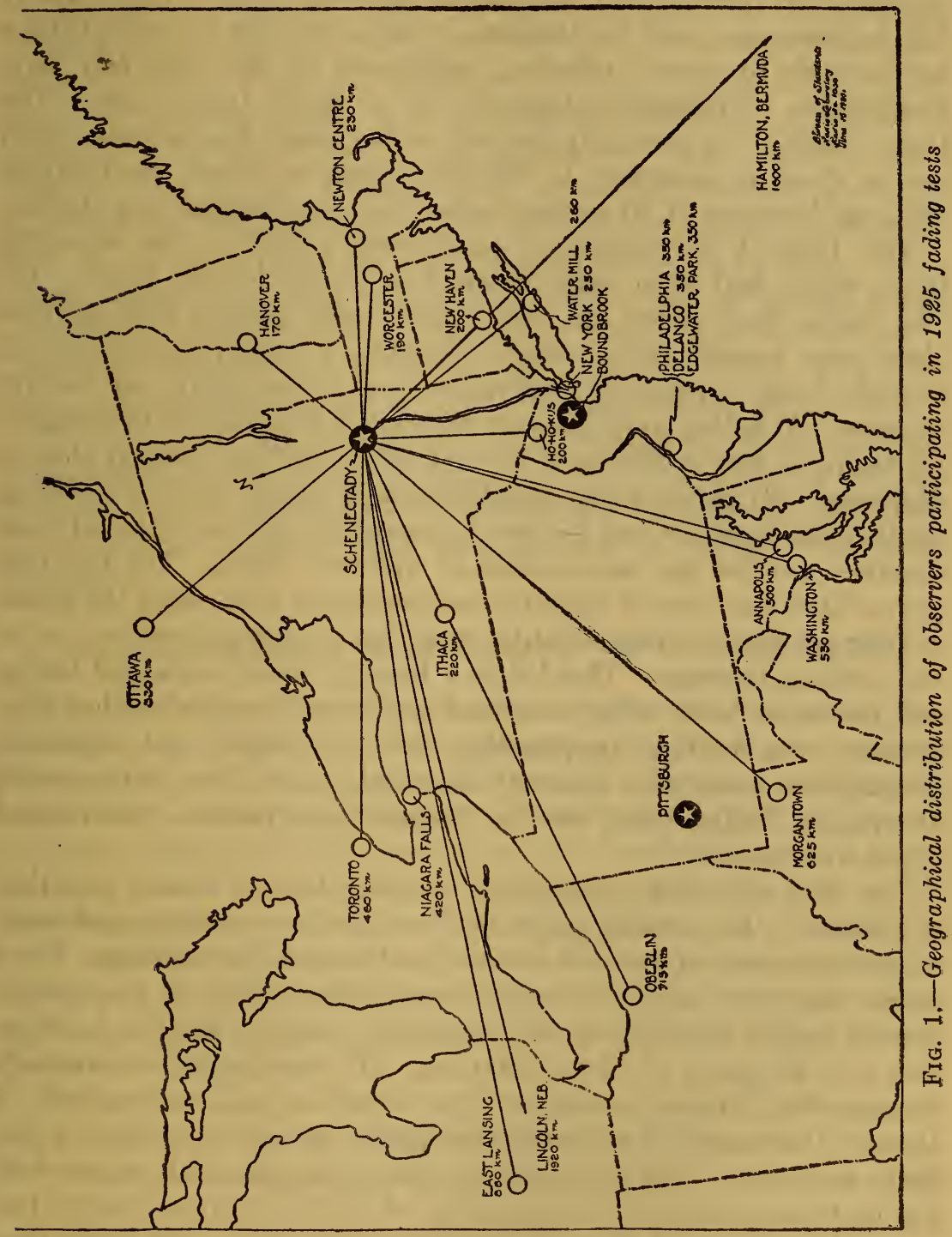

\section{STATUS OF KNOWLEDGE OF FADING}

The seasonal and diurnal variations of received field intensity have been investigated by a number of observers. ${ }^{4}$ It has been

- See "Bibliography on radio-wave phenomena and measurement of radio-field intensities," Bureau of Standards Letter Circular No. 207. 
known for many years that the field intensity fluctuates in an irregular manner; that it is on the average higher at night; that the amount of fluctuation is much greater at night; and that there is a minimum or dip in the field intensity at sunset. These effects all become more pronounced the higher the frequency. ${ }^{5}$ Above about $500 \mathrm{kc}$ there are rapid fluctuations at night, varying in period from a few seconds to several minutes, superposed on the relatively slow fluctuations of intensity characteristic of lower frequencies. The term "fading" is popularly limited to the rapid fluctuations which are so great as seriously to disturb reception. These fluctuations occur at distances of 50 or more miles from the transmitting station.

The 1920-21 investigation ${ }^{6}$ established definitely the following facts, which had been only surmised or partly known before: (a) The fading fluctuations are very erratic, with periods ranging from about one second up to several minutes, a periodicity of several seconds being frequently superposed on a periodicity of several minutes; (b) fading conditions are practically independent of weather; (c) fading is less at distances beyond about $400 \mathrm{~km}$ than at shorter distances; $(d)$ fading is not simultaneous or similar at two receiving points close together, nor for two transmitting stations situated close together, nor for the same station at different times. The last fact proved that the cause of fading is not associated with either the transmitting or the receiving locality, and that it must, therefore, be in the medium between. This led to a theory ${ }^{6}$ which explained fading and has since been widely accepted and used to explain other phenomena, viz, daylight propagation along the earth, and nighttime propagation along the Kennelly-Heaviside layer, free from ground absorption, fading being due to irregular absorption in the ionized upper atmosphere.

The first extended quantitative investigation of fading was that of Pickard. ${ }^{7}$ He devised methods of continuous recording and made extensive records of received waves from broadcasting stations. For a single observing point he secured quantitative data on the characteristic fading throughout the frequency range of 500 to $1,500 \mathrm{kc}$ and over distances of 10 to $2,500 \mathrm{~km}$. He found that the intensity changes from minute to minute by a factor as great as hundreds of times. He showed that perceptible fading occurs at as short a distance as $10 \mathrm{~km}$. For two receiving points separated about one-half $\mathrm{km}$ he found similarity in the fading of several minutes period, but no similarity in the fading of several seconds period. He found that the fading of several seconds period is more pronounced at distances up to $225 \mathrm{~km}$ than at greater distances. So fruitful were Pickard's

- Only frequencies below $3,000 \mathrm{kc}$ are considered here.

- See footnote 1, p. 420.

7 See footnote 3, p. 420. 
observations that it seemed desirable to have similar work done in a number of different localities, and the present investigation was undertaken with this in view.

In a detailed quantitative study ${ }^{8}$ of fading effects at distances within about $150 \mathrm{~km}$ of a broadcast station engineers of the American Telephone \& Telegraph Co. proved that for such distances the characteristic fading is due to interference of wave components traveling over different paths, that it is not simultaneous or similar on different frequencies (even frequencies very close together), and that selective fading can give rise to actual distortion or spoiling of the quality of received signals. This work points clearly to the existence of waves traveling up to the Kennelly-Heaviside layer, undergoing variable changes of intensity, phase, and polarization, and returning to earth to produce fading by interference with the wave propagated directly along the ground (or, conceivably, with other wave components returning from the Kennelly-Heaviside layer).

The facts and theory of fading have been greatly illuminated and corroborated by concurrent investigations ${ }^{9}$ of other radio-wave phenomena, such as variations of wave direction and polarization, effects of the earth's magnetic field, and behavior of waves of very high frequency.

\section{APPARATUS AND METHODS OF MEASUREMENT}

The method used for making a continuous record is essentially that described by Pickard. ${ }^{10}$ The apparatus used by the cooperating laboratories consisted of any one of a number of types of receiving sets used with a rectifier and a sensitive galvanometer in such a way as to indicate variations of the received antenna current as caused by the varying received wave. Figure 2 shows a circuit diagram of the method used to connect the recorder unit (rectifier and galvanometer) to a superheterodyne receiving set. This type of receiving set was used by a large majority of the observers. A photograph of the apparatus as set up and used in the Bureau of Standards laboratory is shown in Figure 3.

The signal is received on an open antenna which, in order to minimize variations due to changes in direction of the radio waves, is preferably nondirectional. The signal is amplified by means of the

\footnotetext{
8 "Some studies in radio-broadcast transmission," R. Bown, D. K. Martin, and R. K. Potter, Proc. I. R. E., 14, p. 57; February, 1926.

" "Why wireless electric rays can bend round the earth," Joseph Larmor, Phil. Mag., 48, p. 1025; Decem. ber, 1924. "Propagation of electric waves over the earth," Nichols and Schelleng, Bell System Tech. J., 4, p. 215; April, 1925. " Some direct evidence for downward atmospheric reflection of electric rays," Appleton and Barnett, Proc. Roy. Soc., 109, p. 621; 1925. "The propagation of radio waves over the earth," Taylor and Hulburt, Phys. Rev., 27, p. 189; February, 1926. "Polarization of radio waves," G. W. Pickard, Proc. I. R. E., 14, p. 205; A pril, 1926. "An investigation of wireless waves arriving.from the upper atmosphere," Smith-Rose and Barfield, Proc. Roy. Soc., 110, p. 580; 1926.
}

10 See footnote 3 , p. 420. 
receiving set. In the plate circuit of the detector tube a transformer tuned to the same frequency as that of the incoming signal (or of the intermediate frequency if a superheterodyne set is used) is inserted in series with the audio-frequency transformer. The secondary of the radio-frequency transformer is in series with a two-electrode electron tube and a sensitive direct-current galvanometer (maximum deflection 10 to 50 microamperes). The deflection due to the continuous current of the two-electrode tube is eliminated by adjusting the tension on the galvanometer suspension so that the galvanometer reads zero when no radio waves are being received. The received waves cause a deflection of the galvanometer which is approximately proportional to the square of the radio-field intensity. In some instances the three-electrode tube was used, the space current being

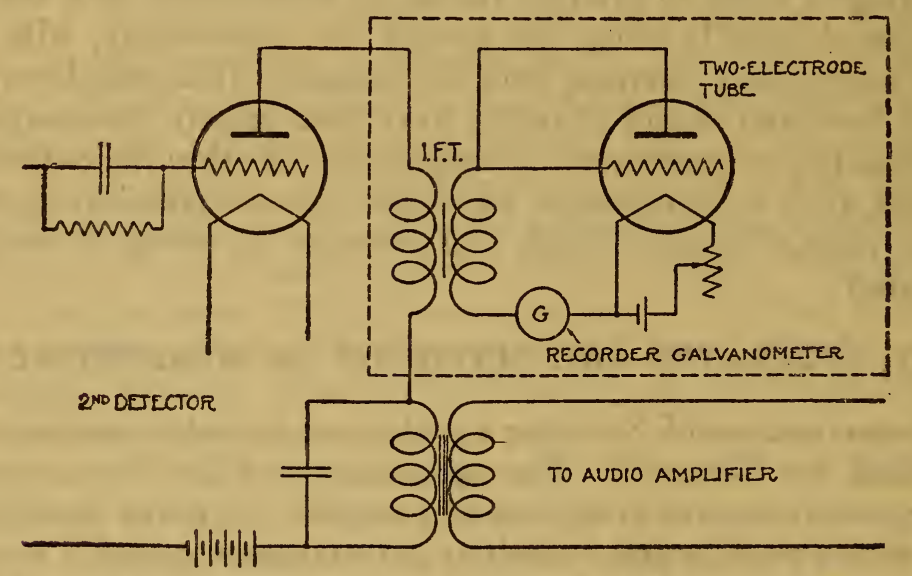

FIG. 2.-Circuit diagram of recorder unit attached to superheterodyne

balanced out by a reverse battery current through the galvanometer. The reading of the galvanometer is transferred to a paper tape on a small moving drum by means of a manually operated lever device. As the operator follows the position of the galvanometer needle by means of an index above it, the pen records on the tape. A photograph of this recording device, which was developed by H. S. Shaw, Newton Center, Mass., is shown in Figure 4. This recorder was used by most of the observers. While convenient, this device is not absolutely essential. Several records were made by observing the position of the galvanometer needle at frequent intervals and plotting the results on cross-section paper. Figure 5 shows samples of records, made by means of the recorder. The divisions along the zero line represent two-minute intervals, while the ordinates represent values which are approximately proportional to the square of the antenna current. Short-period changes, from a few seconds to a few minutes, may be seen at a glance. 
Scientific Papers of the Bureau of Standards, Vol. 22

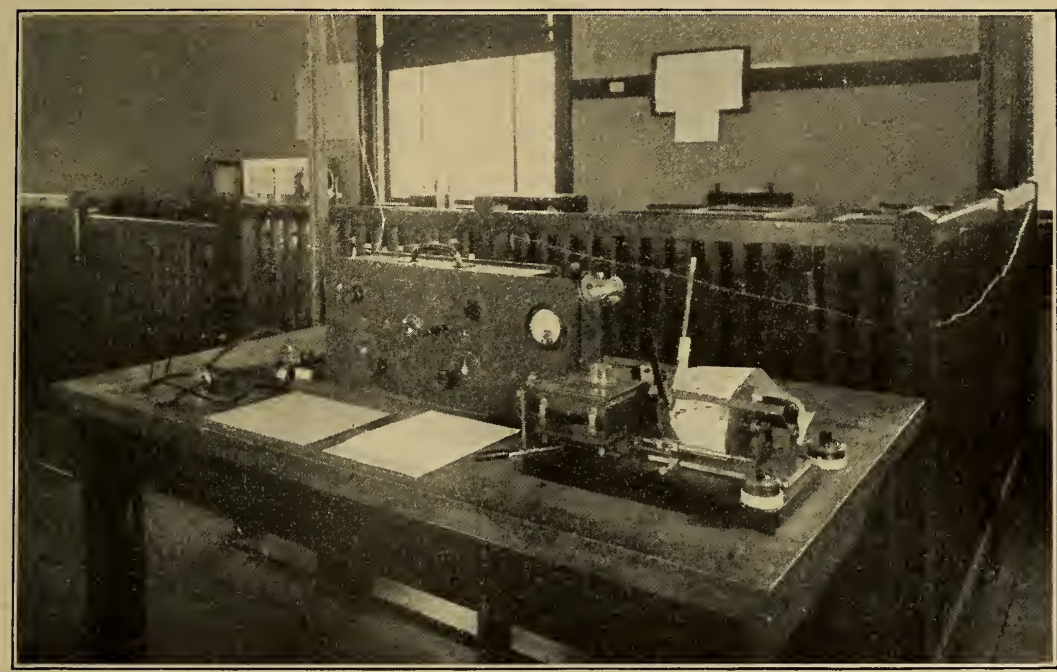

FIG. 3.-Apparatus used at Bureau of Standards to record fading

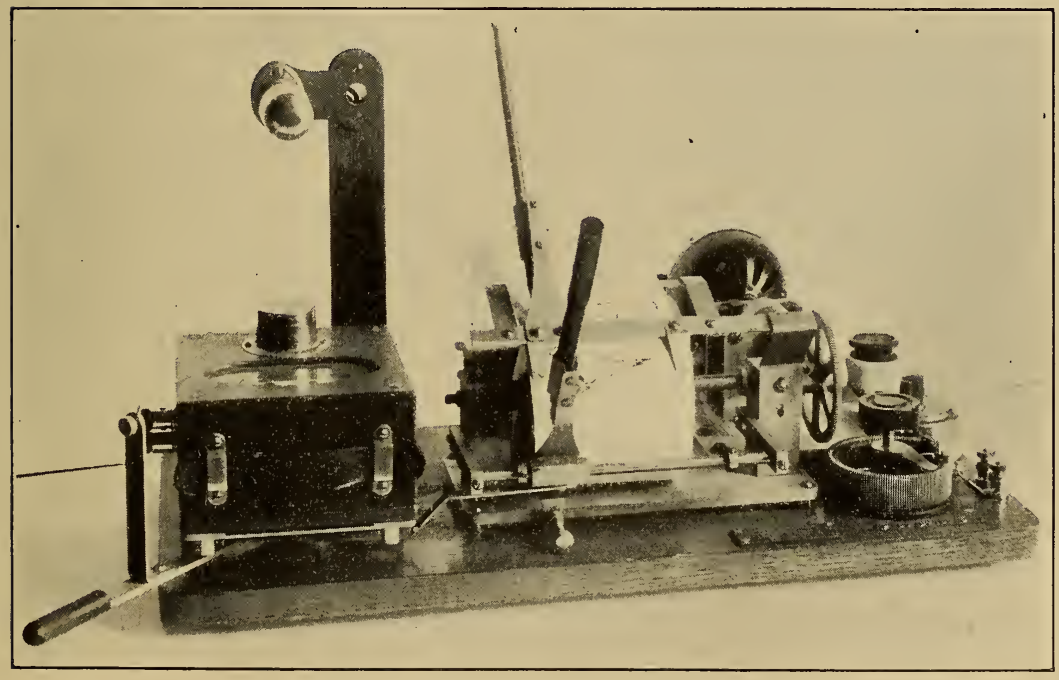

FIG. 4.-The Shaw fading recorder 
Method of analysis.- Since most of the tests were run from 5 to 24 hours, the records to be examined were each from 16 to 75 feet long. The following analysis procedure was adopted:

Contracted graphs are made, showing the mean intensity changes with ordinates which are directly proportional to changes in receiving antenna current. The record is divided into fading cycles of from three to eight minutes' duration, each cycle including a maximum and a minimum of intensity. The mean height of the curve for each fading cycle thus defined is obtained and the value read in terms of the square root of the mean ordinate. This value is called the mean intensity of the fading cycle.

Since the variation in the amount of the more rapid fading throughout the test period seriously affects the quality of reception, a measure of this is obtained. The ratio of the difference between the maximum and minimum ordinate during a fading cycle (defined above) to the mean intensity for the cycle is called the fluctuation. This ratio is used as ordinate for the fluctuation graphs.

In the sunset-fading tests the curves for different days varied widely. In order to obtain an average curve, the values for the local sunsets were averaged and the values for each day multiplied by the ratio of average sunset value to the sunset value for that day. This weighting was done for both the intensity and the fluctuation. curves.

The contracted graphs make available most of the data. There is, however, much information on the character of the fading that is given only by examination of the original records, which are impossible to reproduce in a paper of this kind.

\section{RADIO PHENOMENA DURING SOLAR ECLIPSE}

The cooperative series of tests began with a study of the radio effects of the solar eclipse of January 24, 1925. The meager results of observations during previous eclipses were conflicting, but seemed to indicate perceptible effects partly similar to those of nighttime. It was particularly worth while to organize an observation program during the eclipse of January 24, because the path of the eclipse lay in northeastern United States, where observing laboratories could most readily be enlisted. With the cooperation of G. W. Pickard, the bureau prepared observation outlines and placed the project before a number of laboratories, with the result that 20 laboratories participated in an organized observation schedule. Most of the laboratories were in, or close to, the path of totality of the eclipse.

The general plan of work by each observer was the continuous recording of field-intensity fluctuations of the radio waves from a transmitting station so located that all or part of the wave propagation was in the path of the eclipse. Special signals were con$51407^{\circ}-27-2$ 
tinuously transmitted for this purpose by the broadcasting stations WBZ, of Springfield, Mass.; WGR, of Buffalo, N. Y.; WGY, of Schenectady, N. Y.; and WEAF, of New York, N. Y., each transmitting on its usual broadcast frequency. In order to determine whether any effects observed were due to the eclipse, the observations were made at the same time of day $(7.30$ to $11 \mathrm{a} . \mathrm{m}$.) for several days (January 22 to 26) both before and after as well as during the eclipse. Most of the laboratories observed the fading-that is, fluctuations of radio-signal intensity.

In addition, there was some observation of variation of field intensity from low-frequency stations (from 24 to $57 \mathrm{kc}$ ) and from high-frequency stations $(2,000$ to $8,000 \mathrm{kc})$. At two laboratories, also, measurements of direction variations were made.

The results of the eclipse observations have been fully described in a paper by Mr Pickard. ${ }^{11}$ The effect of the eclipse was, just as expected, the production of a condition intermediate between daytime and nighttime transmission. The variations of radio-wave transmission from day to night depend upon the varying ionization of the atmosphere, and the eclipse doubtless caused a diminution of ionization in the upper atmosphere partially simulating that of night. While the results were erratic and very decidedly masked by fluctuations to which it is not possible to assign any interpretation, there was an effect during the eclipse superposed upon the otherwise meaningless variations, lasting for about an hour and consisting of a decrease in field intensity to a minmum, followed by an increase to a maximum and then a subsidence to normal. This result is exactly similar to the effect of the sunset period, as shown later in this paper. This result was by no means patent in the individual records and was subject to modification depending on the relative locations of transmitting and receiving stations with respect to the path of totality. In some cases the preliminary diminution was not observable, and in other cases the succeeding rise was not observable.

These conclusions were verified in a general way by the reports of observers in a qualitative investigation of the eclipse by broadcast observers organized by the Scientific American. ${ }^{12}$ The following general statements characterize the phenomena:

(a) When the transmitter and receiver were outside the path of totality and on the same side, the effect observed was an increase of field intensity.

(b) When the two were outside the path and on opposite sides, there was a decrease in field intensity, its duration being largely before totality.

11 "The effect of the solar eclipse of Jan. 2A, 1925, on radio reception," G. W. Pickard, Proc. I. R. E., 13, p. 539; October, 1925. See also "U. S. Bureau of Standards eclipse observations," prepared by G. K. Burgess, Sci. Am., 133, p.170; September, 1925.

12 "The effect of the solar eclipse on radio," A. P. Lane and F. X. Walsh, Sci. Am., 132, p. 224; A pril, 1925. 
(c) When both the transmitting station and the observer were within the path of totality, there was a sharp increase in field intensity practically coincident with totality.

\section{SUNSET-FADING TESTS}

The next work done by the group of cooperating laboratories after the eclipse tests was a study of fading during the sunset period. At four different times during the year test periods were arranged. In each test the observers made fading records several hours long on each of six evenings distributed over two weeks.

March 24 to April 2.-The first test ran from March 24 to April 2. Arrangements were made with the General Electric Co., Schenectady, N. Y., to transmit continuously from station WGY for a period of several hours centering at sunset on the six days selected; the normal broadcast frequency, $790 \mathrm{kc}$, was used. Ten laboratories participated in these observations, approximately half of the observers using the fading recorder which gave a continuous record, while the remaining observers took galvanometer readings several times a minute and plotted records. Figure 5 is made up of records obtained during this set of observations.

Figure 6 shows six mean intensity graphs made by analyzing the continuous records made at Washington. These graphs show the large variation from day to day in signals received from a station. To secure the average graph the average sunset value at the receiving point was used as a standard, all the values of each individual curve were multiplied by that factor which would make the sunset value equal this standard, and then these weighted values were averaged according to their position with respect to sunset. The time scale is such that points are plotted according to their position before or after sunset at the recording station, and points of a corresponding number of minutes before or after sunset were averaged. If the centers of measured periods failed to come on corresponding time points, interpolations were made so that all records might have their proper weight in each average. The graph at the top of figure 6 shows the average for Washington; Figure 7 shows the average graph for each receiving point which sent in a sufficient number of records for analysis; Figure 8 shows the average graphs of fluctuation about the mean-field intensity for the different receiving stations. The short vertical lines indicate the sunset time of the transmitting station. As shown in Figure 5, individual records made at a given receiving point have wide differences from day to day in the meanintensity variations occurring at corresponding times with respect to sunset. The average graphs of Figure 7, however, with the exception of the average curve for New York, are fairly uniform in showing 
Sclentlfic Papers of the Bureau of Standards, Vol. 22

NEW YORK CITY,MCH3O

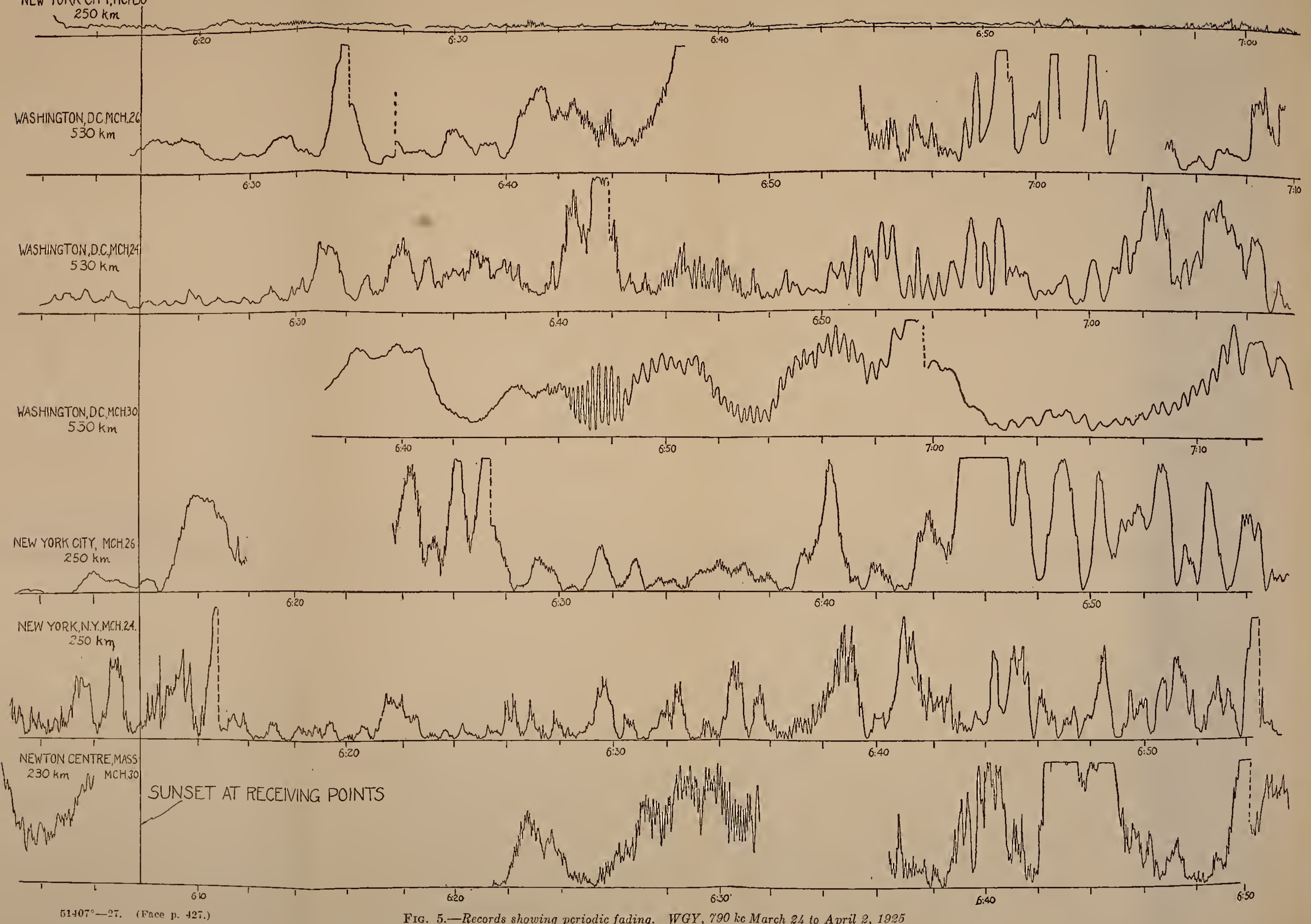




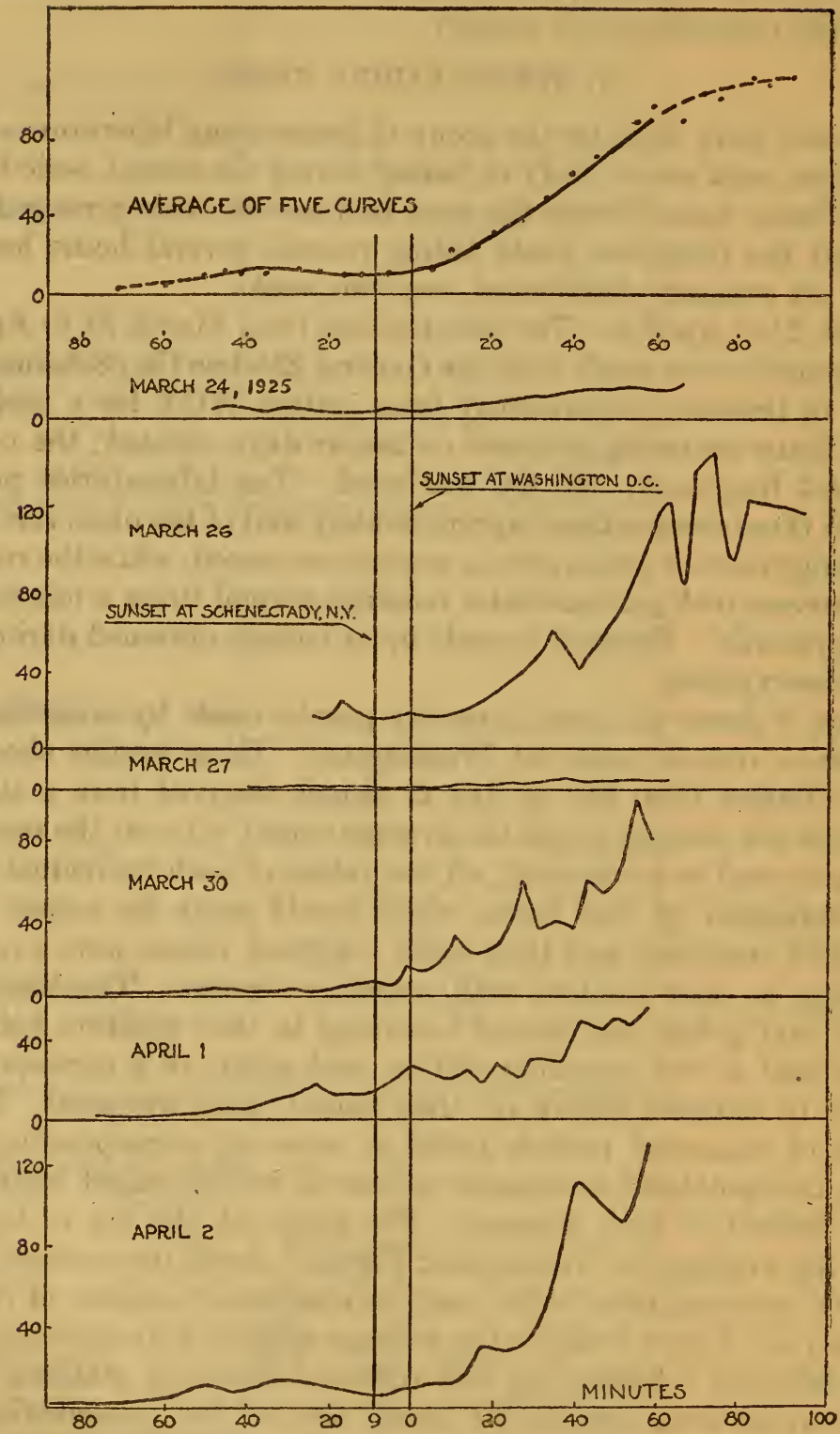

Fig. 6.-Mean field intensity changes in WGY signals as received at Washington during sunset tests of March 24 to April 2, 1925 


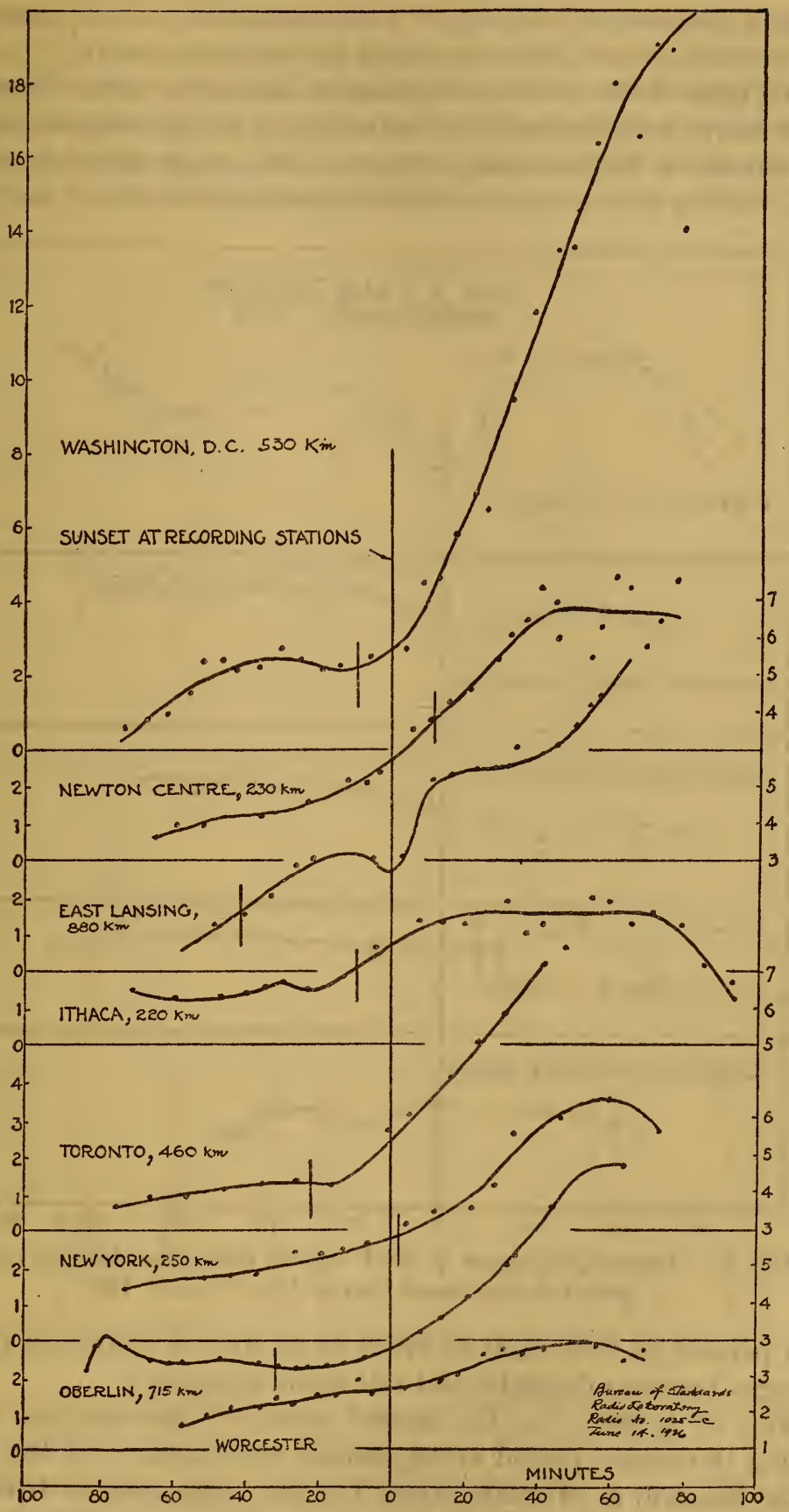

Fig. 7.-Average field intensity changes in WGY signals as received at different observing points during sunset tests of MarchA pril, 1925 
either a decrease in intensity or a decrease in the rate of rise of intensity occurring just before sunset at the receiving point.

In Figure 8 the average fluctuation about the mean shows as the most marked characteristic a reduction of the fluctuation at or near the sunset of the receiving station. The character of records suggests that in future tests it would be desirable to extend the observa-

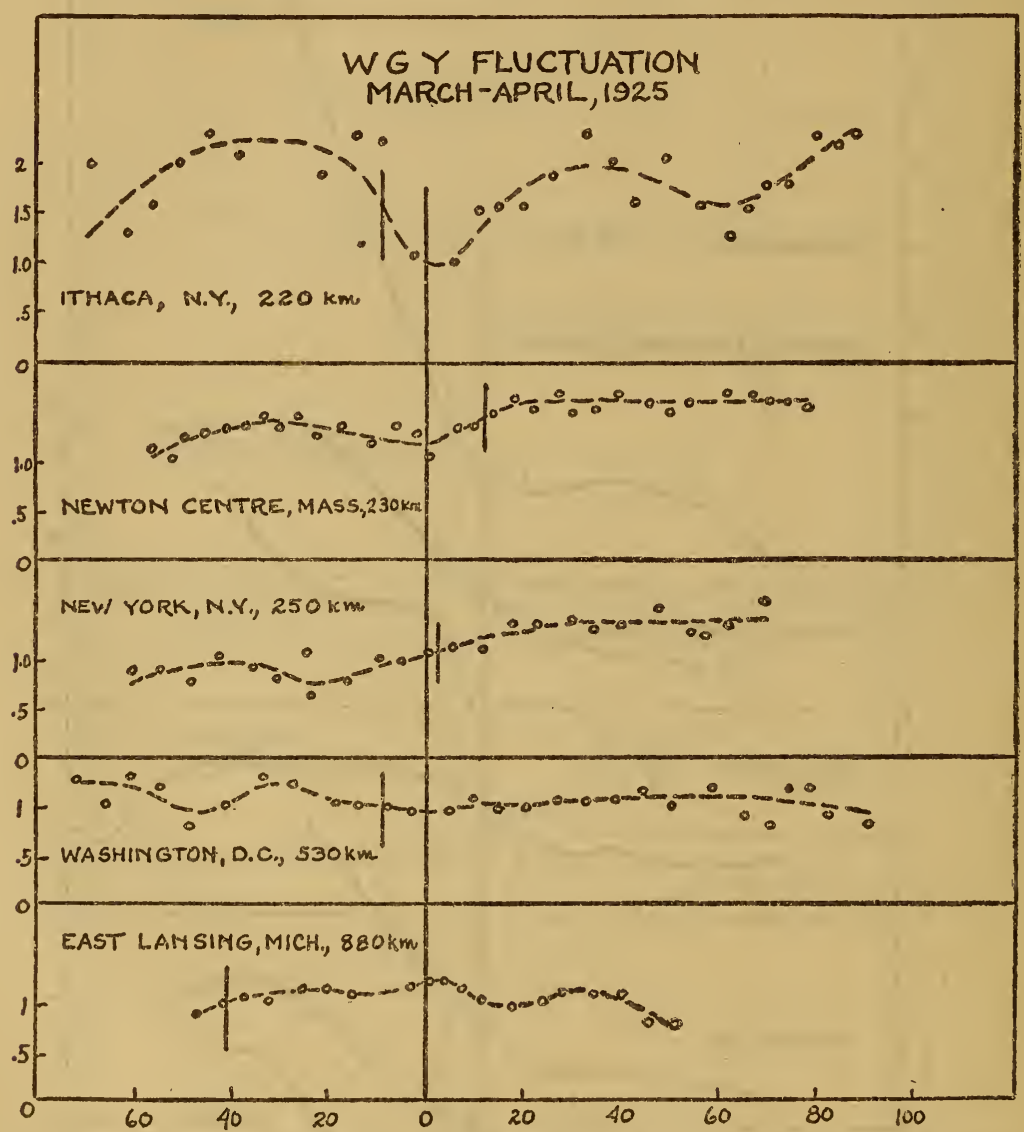

FIG. 8.-Average fluctuation of WGY signals received at different observing points during sunset tests of March-A pril, 1925

tion periods at both ends in order to be sure of including all typical changes between daylight and full-night intensity.

May 19 to 28.-For the second series of observations of fading during the sunset period arrangements were made with the Westinghouse Electric \& Manufacturing Co. for transmissions from station KDKA at East Pittsburgh, Pa., having a frequency of $970 \mathrm{kc}$. As in the previous test, there were six observation periods scattered over a period of approximately two weeks, each test centering at sunset and lasting several hours. Ten laboratories participated in this 
investigation. As in the previous series of observations, records made at the same receiving point on successive transmissions as well as records made simultaneously at different receiving points, are usually quite dissimilar except for the large increase of intensity at or near sunset. A comparison of the records made simultaneously at the Bureau of Standards laboratory and at its field station $5 \mathrm{~km}$

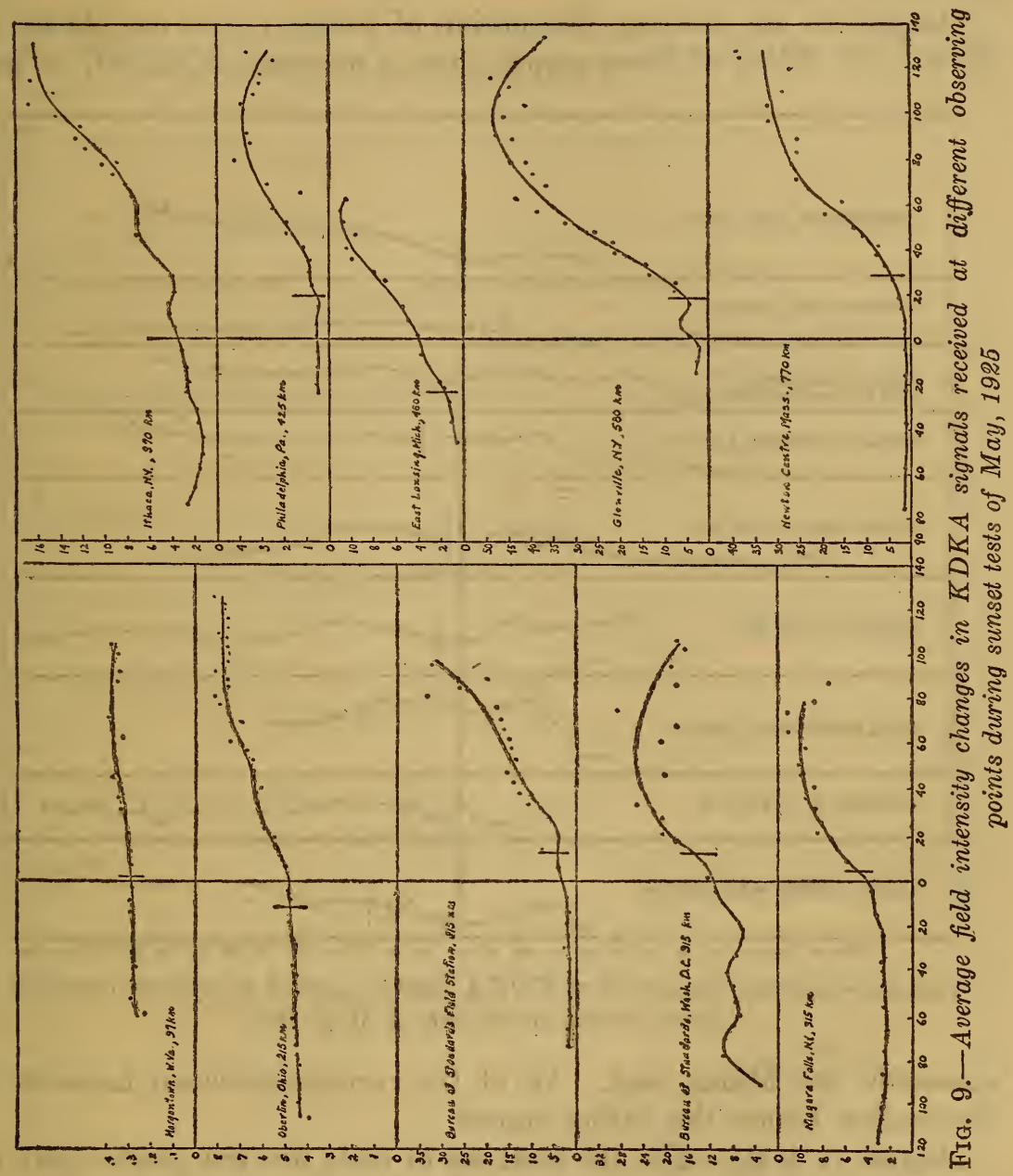

away show some resemblances, such as might be expected in the same general receiving locality. Figure 9 shows the average values of mean intensity for the various receiving points. A reduction in the rate of average-intensity increase near sunset at the receiving station appears.in nearly all the graphs. In some this reduction occurs after sunset. The Morgantown graph shows no definite reduction in the 
rate of increase. In addition to the reduced intensity, such as appeared before sunset on the WGY records, three of these KDKA records show other drops. At Glenville there is a marked dip before the local and another before the Pittsburgh sunset; at Washington there are two marked depressions before either sunset, and at Ithaca one dip before and two after both sunsets. No explanation for this phenomenon is known.

Graphs for the average fluctuation of fading cycles are shown in Figure 10. Most of these graphs show a decrease at sunset, as was

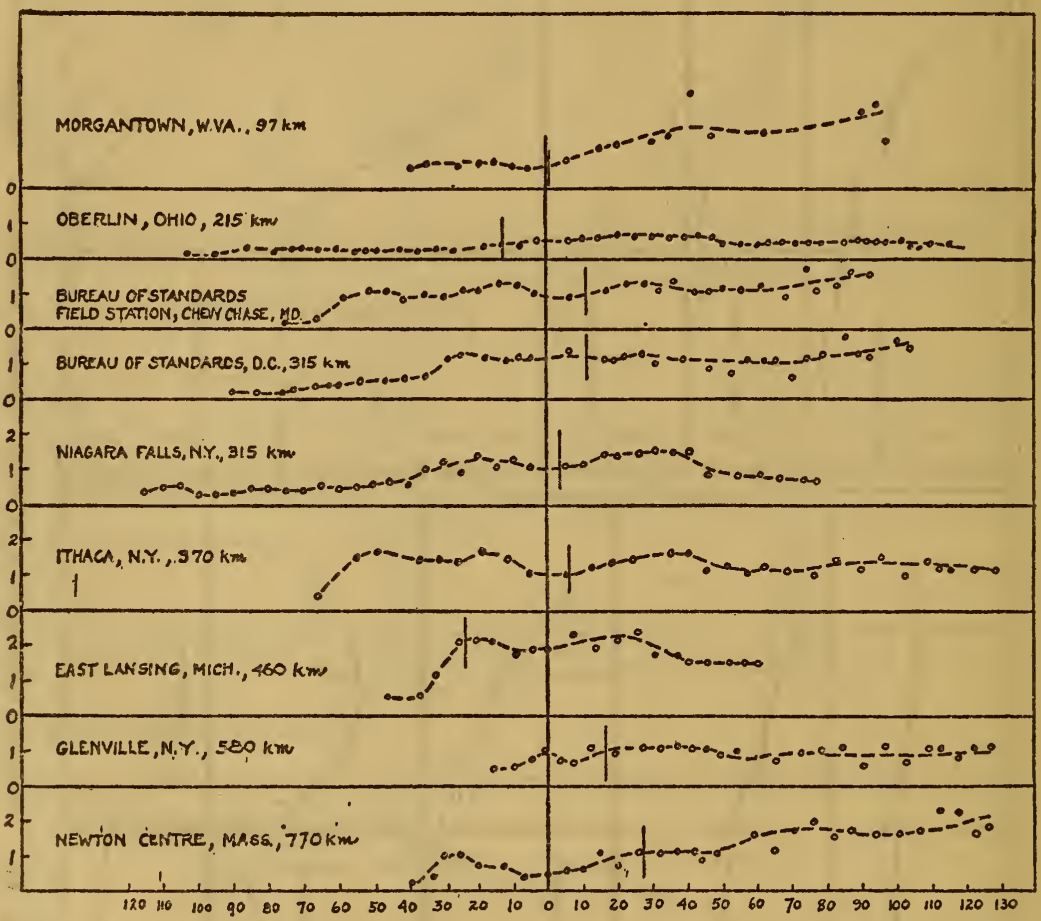

FIG. 10.-Average fluctuation of $K D K A$ signals received at different observing points during sunset tests of May, 1925

shown in the March test. All of the records show an increase in fluctuation before the earlier sunset.

August 11 to 21.-For the next set of tests use was made again of the WGY $(790 \mathrm{kc})$ transmission. The heavy background of atmospherics during the test period made it impossible in most instances to record daylight intensity. The average-intensity and fluctuation graphs are shown in Figures 11 and 12 . The same general characteristics are shown in these records as in the previous ones. The graphs show the decrease at or near the local sunset, as was shown in the earlier test on WGY. 


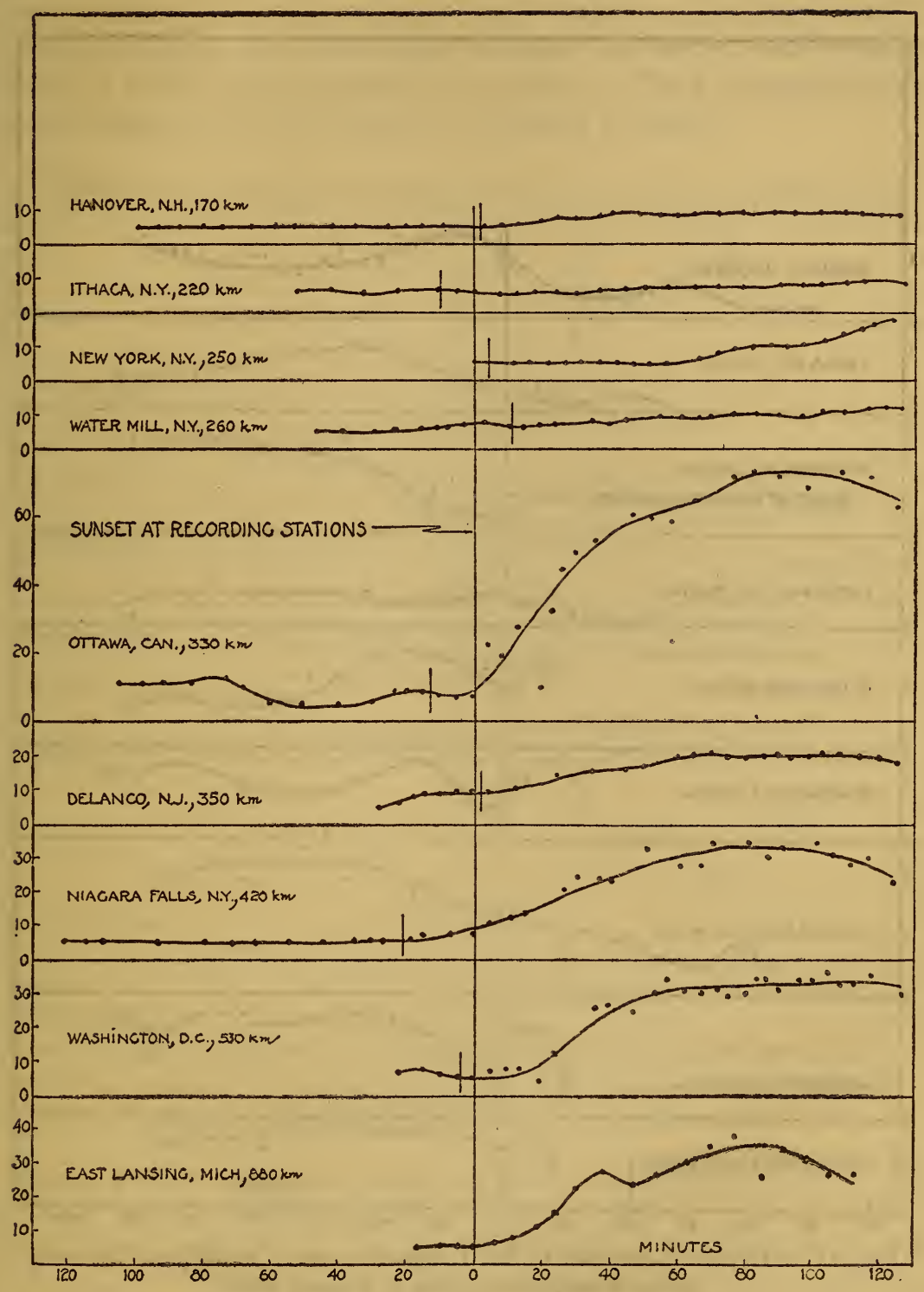

FIG. 11.-Average field intensity changes in WGY signals received at different observing points during sunset tests of August, 1925 $51407^{\circ}-27-3$ 


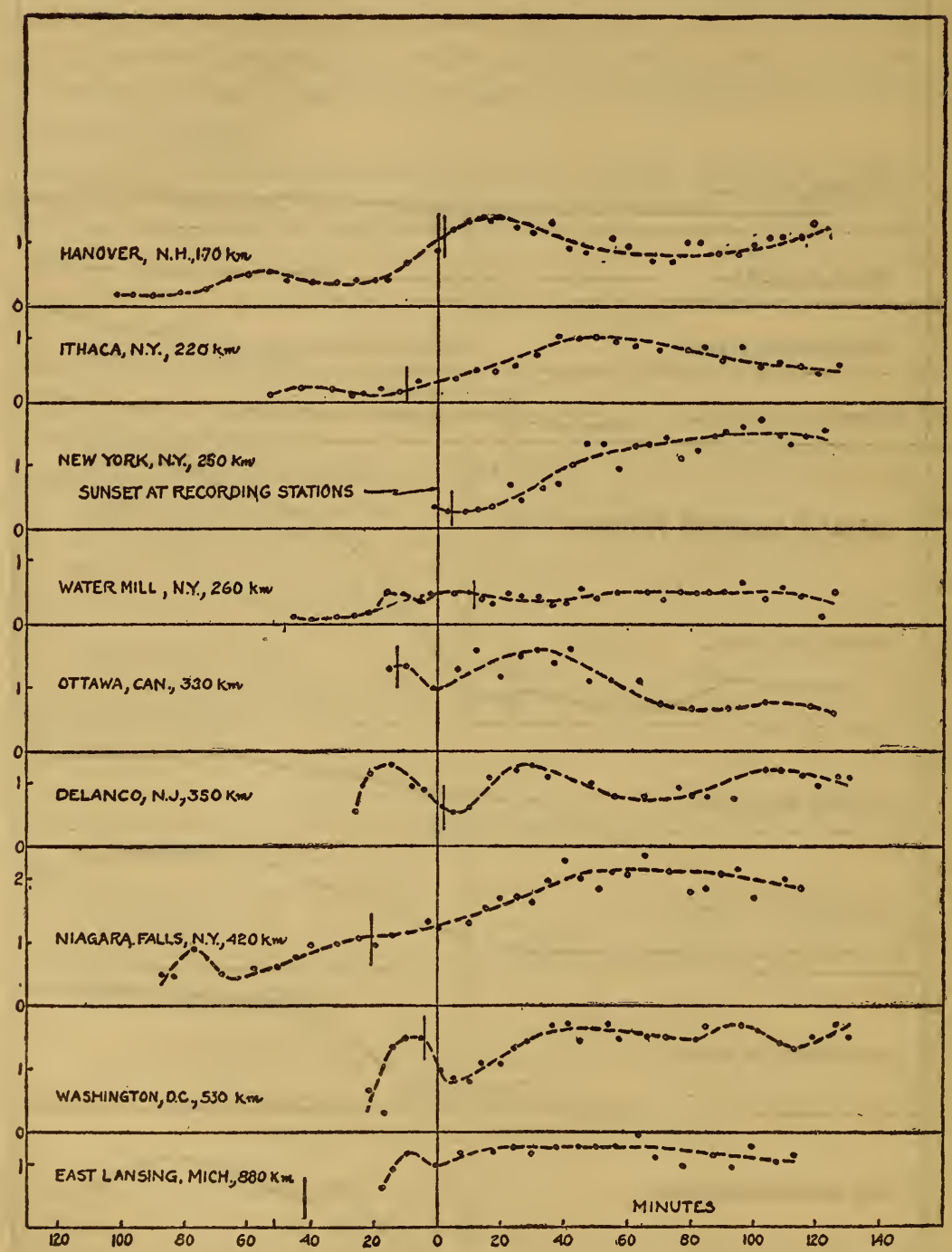

FIG. 12.-Average fluctuation of WGY signals received at different observing points during sunset tests of August, 1925 
December 7 to 17 . - The final series of sunset tests for the year again utilized the WGY $(790 \mathrm{kc})$ transmissions. The records were started earlier in order to observe true daytime intensity; one of the transmissions was continued through 24 hours, and another started at noon and continued for 9 hours. The average-intensity and fluctuation curves are shown in Figures 13 and 14.

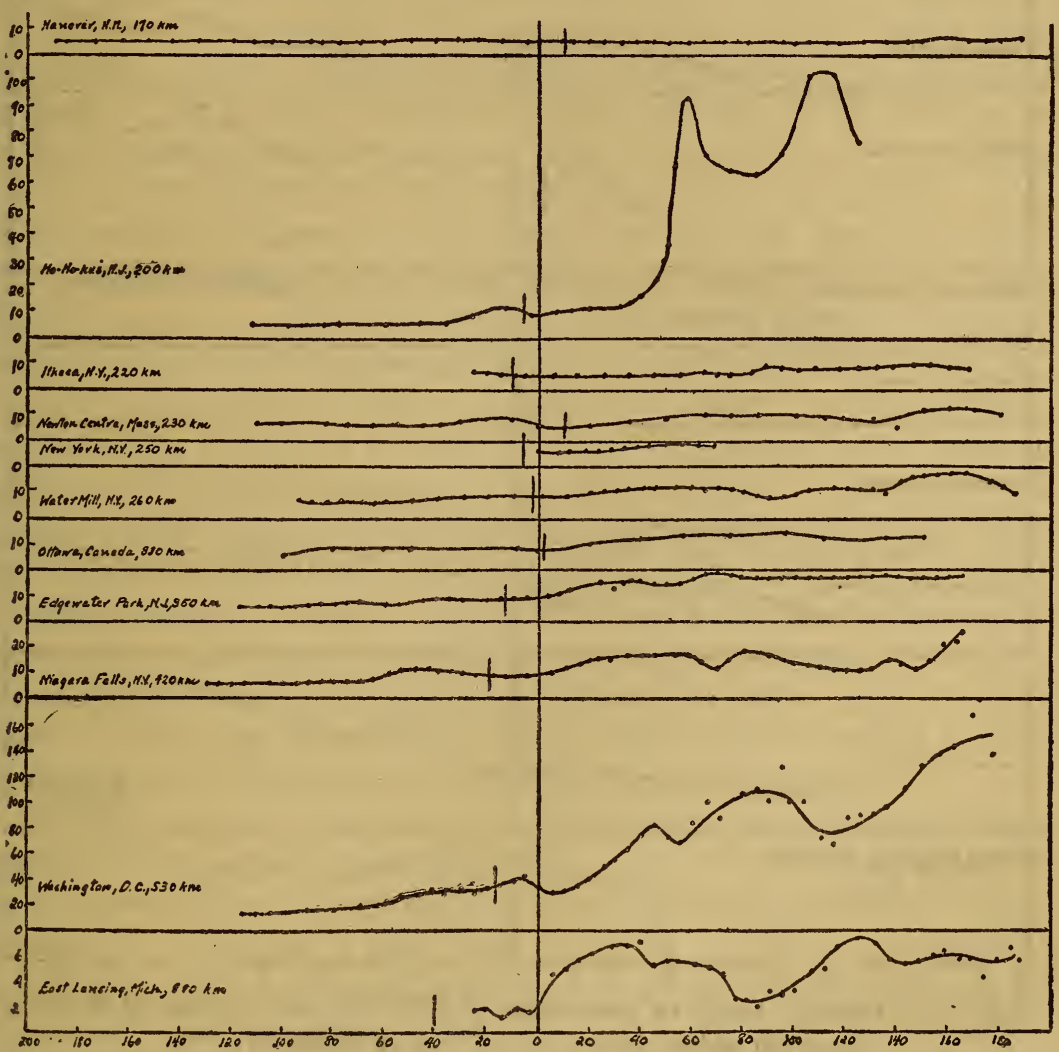

FIG. 13.-Average field intensity changes in WGY signals received at different observing points during sunset tests of December, 1925

These graphs have the same general characteristics as in the previous tests. In the average-intensity graphs all the receiving points show a decrease in the rate of increase of intensity at or near local sunset. The fluctuation graphs, as in the previous tests, show a decrease in fluctuation at or near the local sunset.

General.-The Weather Bureau prepared special evening maps for the days on which the sunset-fading tests were made. A careful study was made of possible correlations between the observed fading phenomena and the weather conditions as shown by these maps. No consistent correlation could be found between good reception 
and the relation of the transmission path to the direction of the isobars or isotherms.

All the results, as shown in the graphs, are in agreement with the theory advanced by Kennelly ${ }^{13}$ and by Nagaoka, ${ }^{14}$ that because of the position of the sunset shadow wall there should be a decrease in

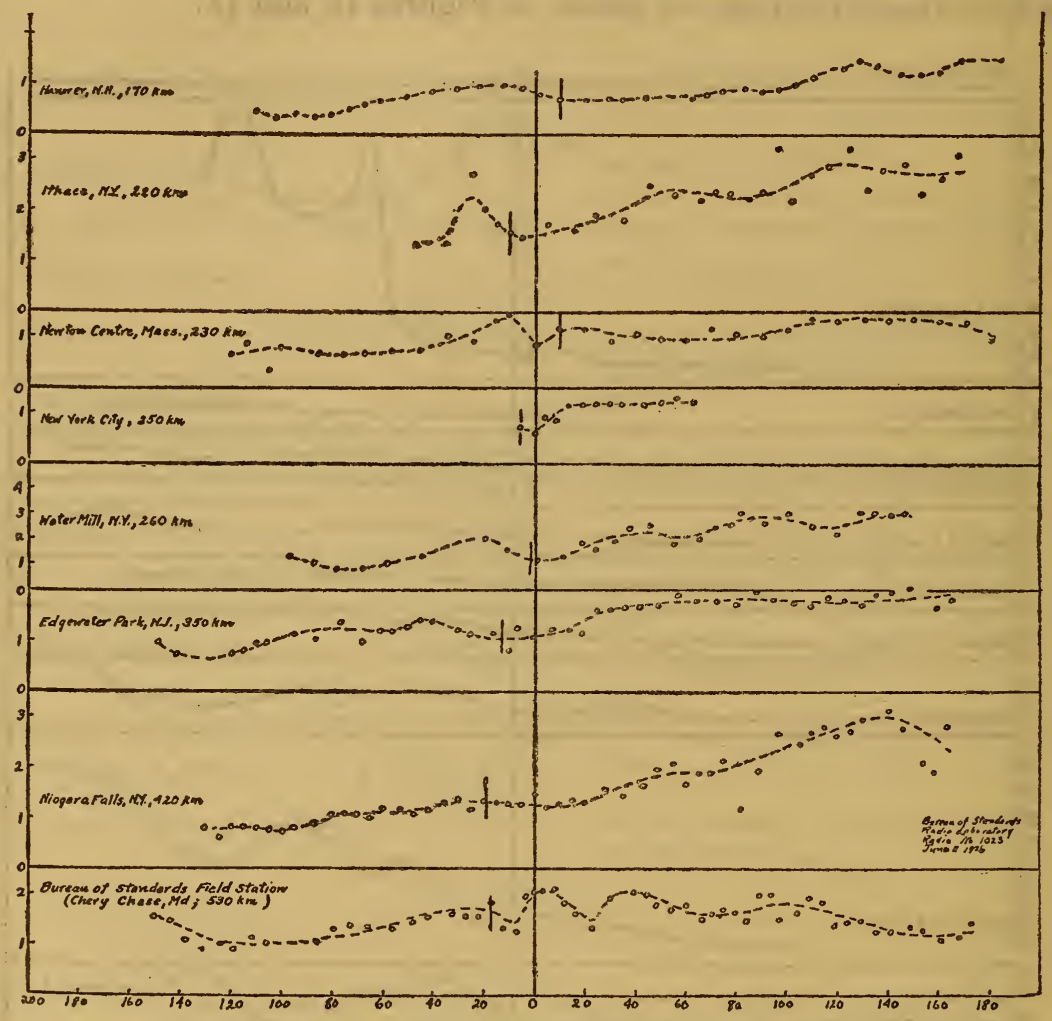

FIG. 14.-Average change in fluctuation of WGY signals received at different observing points during sunset tests of December, 1925

the rate of rise of the average intensity at sunset except in north-andsouth transmissions. In the March-April WGY test the New York record shows no decrease in rate of rise, and in the May KDKA test the Morgantown record shows no decrease. No other receiving stations were either north or south of the transmitting station.

13 "The daylight effect in radio telegraphy," A. E. Kennelly, Proc. I. R. E., 1, pt. 3, p. 39; July, 1913. 14 "Effect of solar eclipse on wireless transwission," Nagaoka, Proceedings mathematico-physical society, Tokio, 7, p. 428; Decomber, 1914. 


\section{SPECIAL PERIODIC TYPE OF FADING}

On seven of the records of the first sunset-fading test (March 24 to April 2) there appeared a regular periodic fluctuation, starting 15 to 20 minutes after sunset at the receiving point and lasting about 25 minutes. This remarkable type of fluctuation repeated its cycle from 2 to 13 (averaging about 5) times a minute. In most instances the character of the fading before and after this periodic fading was of markedly different character, being irregular and having longer periods. The records of Figure 5 show this type of fluctuation.

This phenomenon occurred at three different receiving localities, on three different days, and not simultaneously at different places. The records in Figure 5 are arranged so that the time of sunset at the receiving points coincide, which shows clearly that this type of fading began or ended more nearly at the same length of time after sunset at the receiving point than at the same absolute time.

This phenomenon is the only instance known to the authors in which fading occurs of a character suggesting wave interference of a highly regular type similar to optical interference. This interference is apparently associated with the passing of the sunset shadow plane, for it appears at no other time on any of these records (appearance on other records is noted below). It begins about 15 minutes after sunset, at which time the tangent rays of the sun pass $10 \mathrm{~km}$ above the earth's surface; it ends at about 45 minutes after sunset, when the tangent rays pass about $100 \mathrm{~km}$ above the surface $(96 \mathrm{~km}$ for transmission from Schenectady to Washington, for example).

Considering the path of the tangent rays as the sunset shadow plane, a calculation was made to determine whether reflection of the radio waves from this plane could explain the periodic variation of intensity. The idea is that there would be interference between the wave transmitted along the ground and the wave reflected from the sunset shadow plane. Two successive maxima of intensity are due to the increase of length of path of the reflected wave by one wave length, the increasing length of path being due to the steady rise of the sunset shadow plane. The number of maxima per minute is the rate of increase of length of the wave's path divided by the wave length. A calculation of this number, from the rate of rotation of the earth, the latitude, and other known factors, gave a number much larger than the actually observed number of maxima per minute. It follows that the idea of reflection from the sunset shadow plane is not adequate to explain the phenomenon.

Since the observed number of maxima per minute is less than that calculated on this assumption, it is suggested that the effective reflecting surface is not the sunset shadow plane but is some plane at a lower level, or rather that the phenomenon is not one of simple 
reflection but of refraction in the ionized region of the air. The lower surface of the ionized stratum of the atmosphere undoubtedly rises as sunset proceeds, and the effective refracting region rises higher and higher. The effective refracting region is evidently well below the sunset shadow plane and rises at a considerably slower rate.

The fact that the periodic fading ends when the sunset shadow plane is about $100 \mathrm{~km}$ above the earth's surface indicates that the atmospheric region which is capable of rapid change of ionization by change of sunlight is located entirely below that level. Above 100 $\mathrm{km}$ the air is so rare as to be permanently ionized. At the ground, however, the air has little or no ionization, because the ionizing ultra-violet radiations from the sun are progressively absorbed as they pass through the earth's atmosphere, which is of increasing density as the earth's surface is approached. Fifteen minutes after sunset, when the rising shadow plane has reached the height of $10 \mathrm{~km}$ the ions begin to recombine at the level at which the sunlit air has a just appreciable amount of ionization, and the lower surface of the ionized region thus begins to rise. As the shadow plane rises into the rarer air, the recombination of ions proceeds more slowly because of their greater mean free path, and the effective wave-refracting region rises more slowly; this tends to make the observed number of interference maxima per minute decrease, as observed. When the wave-refracting region has risen to the level of permanent ionization (100 km or less), the process of changing height of the wave-refracting region must necessarily come to an end; and the fact that the periodic fading terminates abruptly on the records indicates that there is a fairly sharp discontinuity at the lower surface of the permanently ionized region. The foregoing is in harmony with knowledge from other sources on the mode of propagation of radio waves and adds a new type of evidence corroborating the hypothesis propounded ${ }^{15}$ by one of the authors in 1921, that the effective region controlling radiotransmission phenomena is that portion of the atmosphere below the Kennelly-Heaviside layer.

This theory requires that the number of maxima per second should vary directly with the radio-wave frequency and inversely with the distance from transmitting station to receiving point. The authors have no data on the effect of varying wave frequency, but the inverse variation with distance is clearly established by an inspection of the records. Consider the Washington, New York, and Newton Center records. The periodicity on the Washington records (530 km from Schenectady) is six or more per minute at the beginning and two to three per minute at the end of each time when

15 See footnote 1, p. 420 . Note particularly Figure 9 of B. S. Sci. Paper No. 476, showing the ionized region bounded at heights of 10 and $100 \mathrm{~km}$. 
the periodic fading was observed. The New York and Newton Center records, each $240 \mathrm{~km}$ from Schenectady, show 12 per minute at the start and 7 to 8 at the end.

While this regular periodic fading is relatively rare, an examination of records taken by other observers, either in the past or in the future, would doubtless yield other examples and throw additional light on its nature and cause. The authors have noted its occurrence in the sunset-fading record reproduced as Figure 2 of "On some direct evidence for downward atmospheric reflection of electric rays," by Appleton and Barnett, Proc. Roy. Soc. A., 109, p. 621; 1925. It has also been observed in a few instances on other records by the authors at times other than at sunset, especially at frequencies of the order of $6,000 \mathrm{kc}$. At such frequencies it occurred at various times during a day and lasted for only a few minutes at a time, having various periods for different times. This suggests that the sunset shadow plane is not the only possible cause of such interference phenomena. Any other ionization-affecting surface which is moving relatively to the earth's surface (possibly cloud shadows) might be a cause.

This type of periodic fading presumably occurs only when atmospheric conditions between the transmitting and receiving stations are extremely uniform. No data on this point are available for the observations reported in this paper. In future instances where the regular periodic type of fading is observed, it would be worth while to make careful record of all available data on the state of the weather and of atmospheric electric conditions.

This demonstration of the rôle of the changing ionization produced by sunset throws light on numerous pecularities of radio transmission at and after sunset which have been observed in the past. It is suggested that the rising ionization level produced by sunset has for a limited-time period the same functions as the Kennelly-Heaviside layer; these functions include the causing of fading and the increase of wave intensity at great distances. The mechanism is probably the same; in fact; while we have spoken of a rise of the lower surface of the ionized region, there is probably not so sharp a discontinuity as an actual surface, but simply a region of relatively great rate of change of ionization with height; this is true both of the ionized region causing the sunset effect and of the Kennelly-Heaviside layer. 


\section{TWENTY-FOUR-HOUR FADING TEST}

This test was run as part of the December WGY series to find out what conditions prevail throughout the 24 hours. The average graphs for the 24-hour records are shown in Figures 15 and 16. These nine records show the change in average intensity and fluctuation from noon, December 9, to noon, December 10, 1925. In these records the maximum intensity in all instances occurs approximately

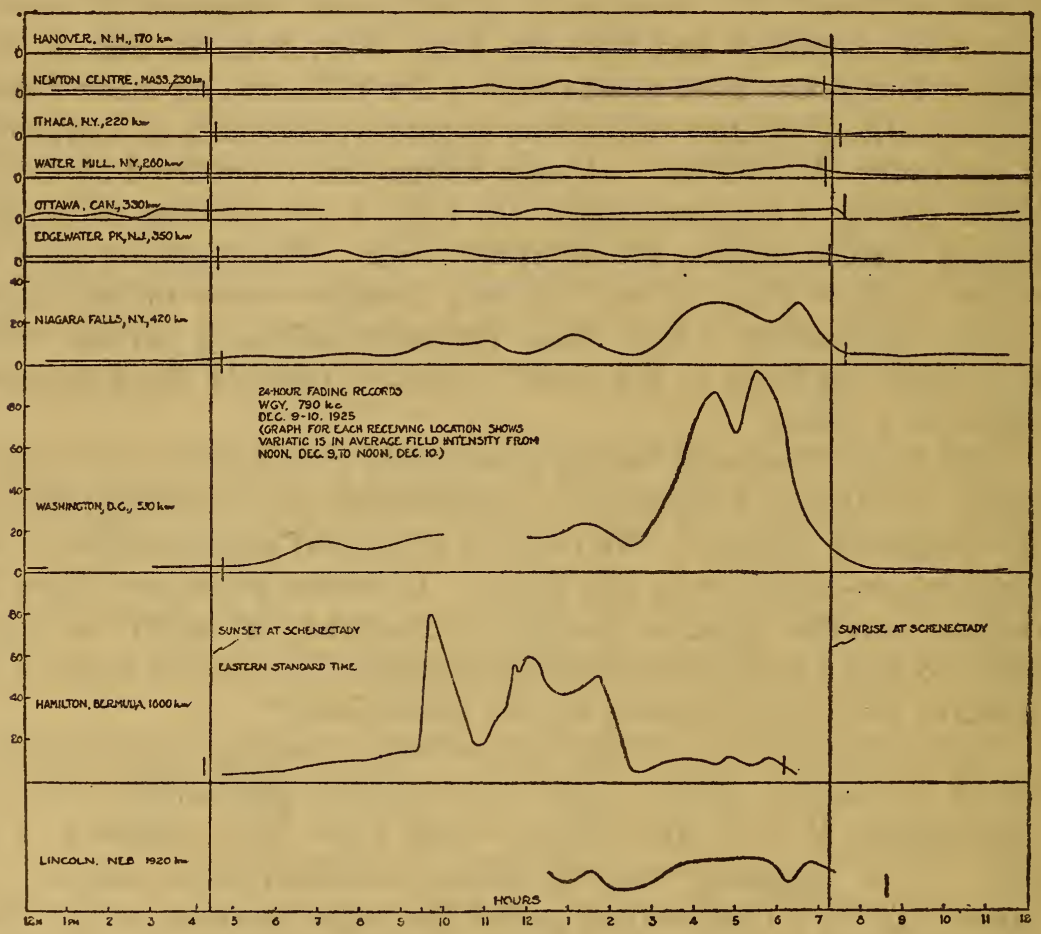

Fig. 15.-Mean field intensity changes in WGY signals received at different observing points during 24-hour test of December 9 and 10,1925

during the three hours preceding sunrise, except in the case of the record made at the greatest distance, in which the maximum occurred approximately at midnight. The graphs of average fluctuation for these same records show increased fluctuation during the hours of darkness. The Washington record is of interest in that the sunset and sunrise effects are similar, but in the reverse order. Since this record is for one day only, it does not warrant the drawing of positive conclusions. 


\section{EFFECT OF HIGH POWER ON FADING}

At the request of the Department of Commerce the General Electric Co. conducted a series of special transmissions from station WGY on the nights of August 22, 24, and 25. The regular broadcast program was transmitted alternately for 15 -minute periods with

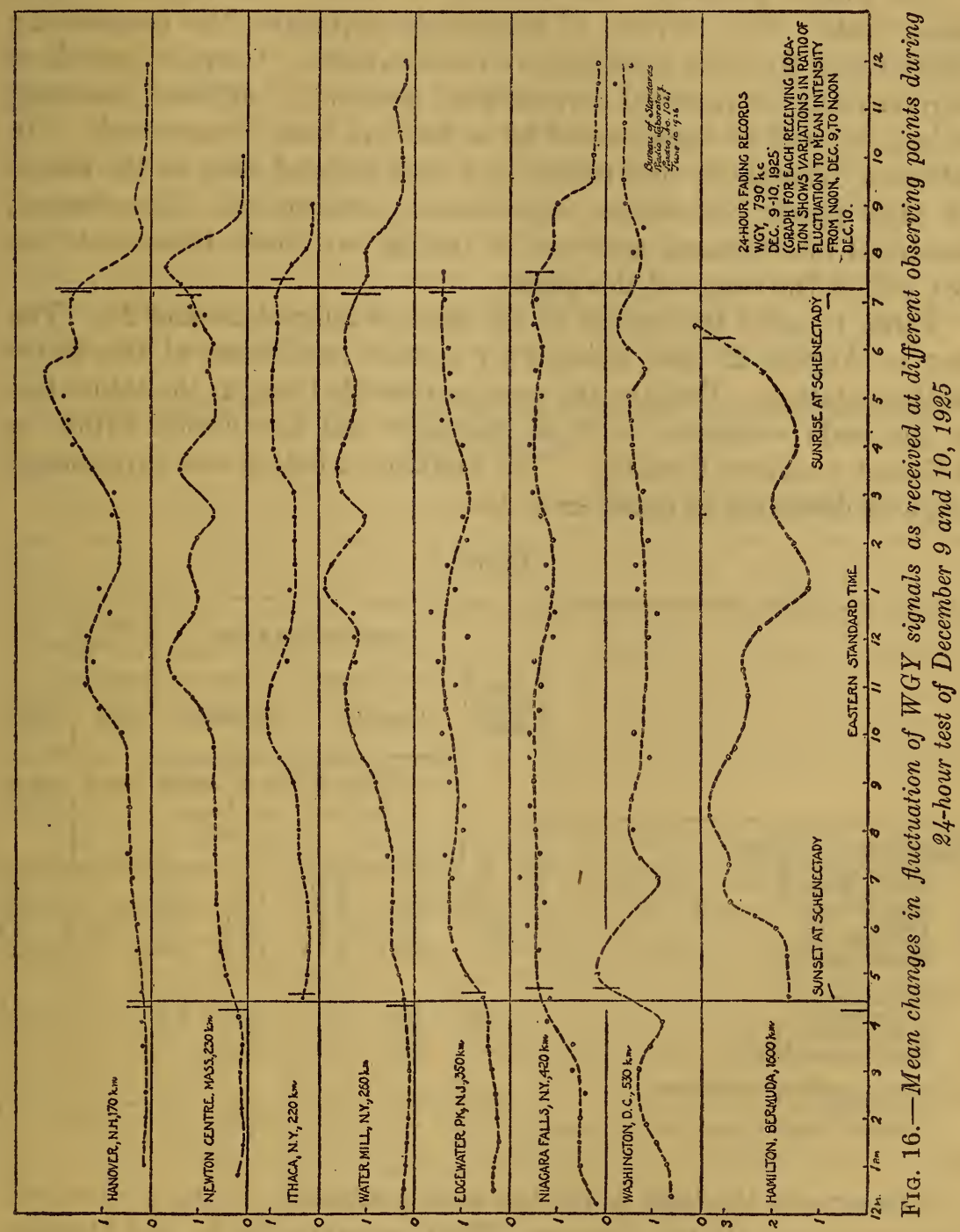

50 and $2.5 \mathrm{kw}$. The purpose of the tests was to determine the effects upon broadcast reception of the use of higher power than had previously been attempted in broadcasting. On August 25 an extra test was conducted from 11 to $12 \mathrm{p}$. m., using 10 and $2.5 \mathrm{kw}$ alternately. 
The 2.5 and the $10 \mathrm{kw}$ transmissions were from the regular WGY multiple-tuned antenna, located at the General Electric plant in Schenectady, whereas the $50 \mathrm{kw}$ transmission was from a vertical antenna at the experimental station located $6 \mathrm{~km}$ away, at South Schenectady. A frequency of $790 \mathrm{kc}(380 \mathrm{~m})$ was used throughout.

The public generally was invited to make observations during these tests. The Bureau of Standards requested the cooperating laboratories to make quantitative observations. Graphic records of variations of the received current were made at 12 different receiving points, located at distances of 40 to $500 \mathrm{~km}$ from Schenectady. In addition to intensity and fading, the tests yielded data on the effects of high power on station interference, atmospheric disturbances, electrical interference, and ease of tuning out; these latter data are not within the scope of this paper.

Table 1 shows the results of the tests of August 24 and 25. The test of August 22 was vitiated by certain conditions at the transmitting station. Perhaps the most noticeable thing in the tabulation is the wide variation, both in intensity and fluctuation ratios, in different receiving localities. The amount of fading was surprisingly large at distances as small as $40 \mathrm{~km}$.

TABLE 1

\begin{tabular}{|c|c|c|c|c|c|c|c|}
\hline & & & atio for 50 & 0 to $2.5 \mathrm{k}$ & & $\underset{2.5}{\text { Ratio ff }}$ & $\begin{array}{l}\text { or } 10 \text { to } \\
\mathrm{kW}\end{array}$ \\
\hline & $\begin{array}{c}\text { Dis- } \\
\text { tance } \\
(\mathrm{km})\end{array}$ & Inter & nsity & Flucts & dation & Inten- & $\begin{array}{l}\text { Flue- } \\
\text { tuation }\end{array}$ \\
\hline & & Aug. 24 & Aug. 25 & Aug. 24 & Aug. 25 & Aug. 25 & Aug. 25 \\
\hline $\begin{array}{l}\text { North-south transmission: } \\
\text { Coeymans, N. Y }\end{array}$ & & 2.3 & & 0.5 & & & \\
\hline $\begin{array}{l}\text { Hudson Falls, N.Y... } \\
\text { New Y ork, N. Y... }\end{array}$ & 60 & 5 & 0.9 & & 1.0 & 1.7 & $0 . \overline{9}$ \\
\hline Nelanco, N.J. & 330 & $\begin{array}{l}1.5 \\
3.4\end{array}$ & $\begin{array}{l}1.8 \\
1.7\end{array}$ & $\begin{array}{l}1.0 \\
.9\end{array}$ & .9 & & \\
\hline $\begin{array}{l}\text { Frankiord, } \mathrm{Pa} \\
\text { Washington, } \mathrm{D}, \mathrm{C}_{-.-}\end{array}$ & 510 & $\begin{array}{l}2.5 \\
3.3\end{array}$ & $\begin{array}{l}2.5 \\
3.6\end{array}$ & $\begin{array}{l}1.3 \\
1.0\end{array}$ & $\begin{array}{l}.7 \\
1.0\end{array}$ & 2.0 & 1.9 \\
\hline West transmission: & & & & & & & \\
\hline $\begin{array}{l}\text { Ithaca, N. Y } \\
\text { Niagara Falls, N. Y }\end{array}$ & $\begin{array}{l}210 \\
400\end{array}$ & $\begin{array}{l}1.6 \\
2.0\end{array}$ & $\begin{array}{l}1.4 \\
1.5\end{array}$ & $\begin{array}{r}.9 \\
.8\end{array}$ & .7 & .9 & 1.0 \\
\hline East Lansing, & 850 & 4.8 & 1.8 & .7 & .7 & 1.3 &.$\overline{7}$ \\
\hline $\begin{array}{l}\text { Northwest-southeast transmission: } \\
\text { Water Mill, N. Y Y }\end{array}$ & & & & & & & \\
\hline Ottawa, Canada & 310 & 1.4 & 1.6 & 1.0 & 1.5 & 1.2 & 1.1 \\
\hline
\end{tabular}

The ratio of the high to the low power intensity in any given direction increases with the distance. The Coeymans, N. Y., and Delanco, N. J., figures alone disagree with this. This conclusion is strengthened by a comparison with measurements made very close to the station, the observed value of the ratio at $5 \mathrm{~km}$ being 1.2 , which is, with a negligible exception, lower than all values obtained at greater distances. 
The ratio of received intensity at high and low power was very small in comparison with the variation of either from instant to instant. The ratio was surprisingly small; this was in part due to the fact that the transmissions with the 50 and the $2.5 \mathrm{kw}$ were from two different antennas and the antenna used for the $50 \mathrm{kw}$ wkas a poor radiator.

The very large fluctuations of intensity averaged the same on high and low power, although for any one place or time the average fluctuation might be greater for either the low or the high power. This conclusion, based on actual analysis of the records, means that fading fluctuation is unaffected by variations of transmitting power. In spite of this, a majority of observers reported that fading was somewhat less on the 50 than on the $2.5 \mathrm{kw}$. This means that, while the percentage fluctuation averaged the same for the two powers, the received-signal intensity did not fall as low for the 50 as for the $2.5 \mathrm{kw}$ and did not as frequently fall below audibility.

\section{INTENSITY AND FLUCTUATION AS FUNCTIONS OF DISTANCE}

Fairly definite relations between average intensity and distance, and some relation between average fluctuation and distance, are indicated in the results of the tests of May 19 to 28, August 11 to 21, and December 7 to 17. The intensity-distance relation is brought out by an examination of the ratio of nighttime average intensity to daytime average intensity. Figures 17 and 18 show the ratio of night to day average intensity, plotted with respect to the distance between transmitting and receiving stations for the three different tests.

Figure 19 shows the average maximum night fluctuation plotted against distance. For the KDKA data a smooth graph was drawn, having maxima at approximately 100 and $400 \mathrm{~km}$ and minima at approximately 200 and $600 \mathrm{~km}$. This graph appears to fit the small number of points available. It is of interest to compare this graph with Figure 8 of the bureau's paper ${ }^{16}$ on the statistical study of conditions affecting distance range, which study was made in connection with this station. The first maximum of fluctuation in Figure 19 is at about the same distance as the first point for minimum reliability of reception in the earlier paper, and conversely the first minimum of Figure 19 is at about the same distance as the first point for maximum reliability of reception in the earlier paper. The present frequency of KDKA, $970 \mathrm{kc}$ is considerably higher than those used in the earlier study, viz, 833 and $750 \mathrm{kc}$. The maximum fluctuation at approximately $100 \mathrm{~km}$ was also indicated in the early Bureau of Standards study of fading. ${ }^{17}$ 
For the WGY tests there were no observers closer than $170 \mathrm{~km}$ to the station and none between the distances of 530 and $880 \mathrm{~km}$. Consequently the first maximum, as well as the manner of variation at the extreme distances, is uncertain. It is possible, however, to draw similar curves for the three series of tests, each curve including every point which represents an average of the complete series of observations for a given observation point. Only when the average represents less than six records does the point fail to coincide with the curve. The most distant value, for instance, is averaged from only

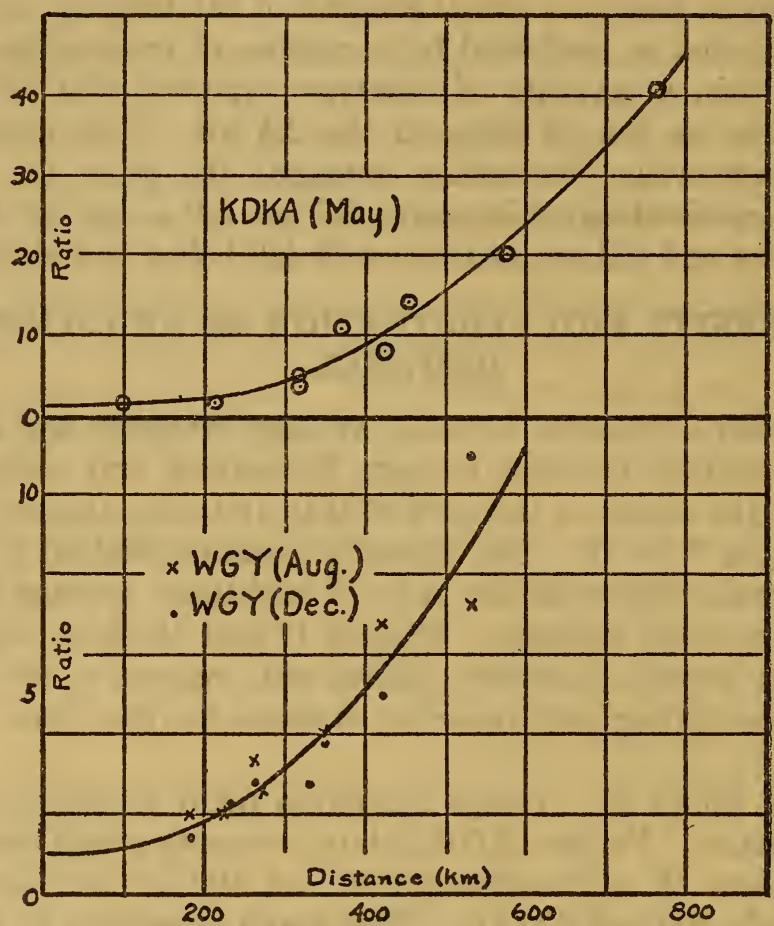

FIG. 17.-Increase in ratio of night to day average intensity with distance from transmitting station

three records. The August and December graphs of Figure 19 may therefore be considered a fair suggestion of the general manner in which fluctuation of $790 \mathrm{kc}$ transmission varies with distance. The first maximum ât $150 \mathrm{~km}$ approximately coincides with the distance to which Pickard ${ }^{18}$ ascribes maximum fading. The first minmum is at approximately $275 \mathrm{~km}$, and the second maximum, apparently equal to the first, occurs at a distance of something like $425 \mathrm{~km}$. Beyond this distance there is suggested a very broad minimum and a flattening effect. While these maxima and minima for the WGY

${ }^{18}$ See footnote 3, p. 420 . 
data are somewhat displaced from the corresponding features of Figure 8 of the bureau paper, referred to above, they are nevertheless consistent with the interpretation of this graph. The maximum fluctuation in August is noticeably less than during the cooler months. This would be expected, since the minimum absorption is greater in hot weather, and therefore the possible range of variation is less.

The graph (fig. 17) for the ratio of night to day average intensity shows an increase of ratio with distance. It is significant that the

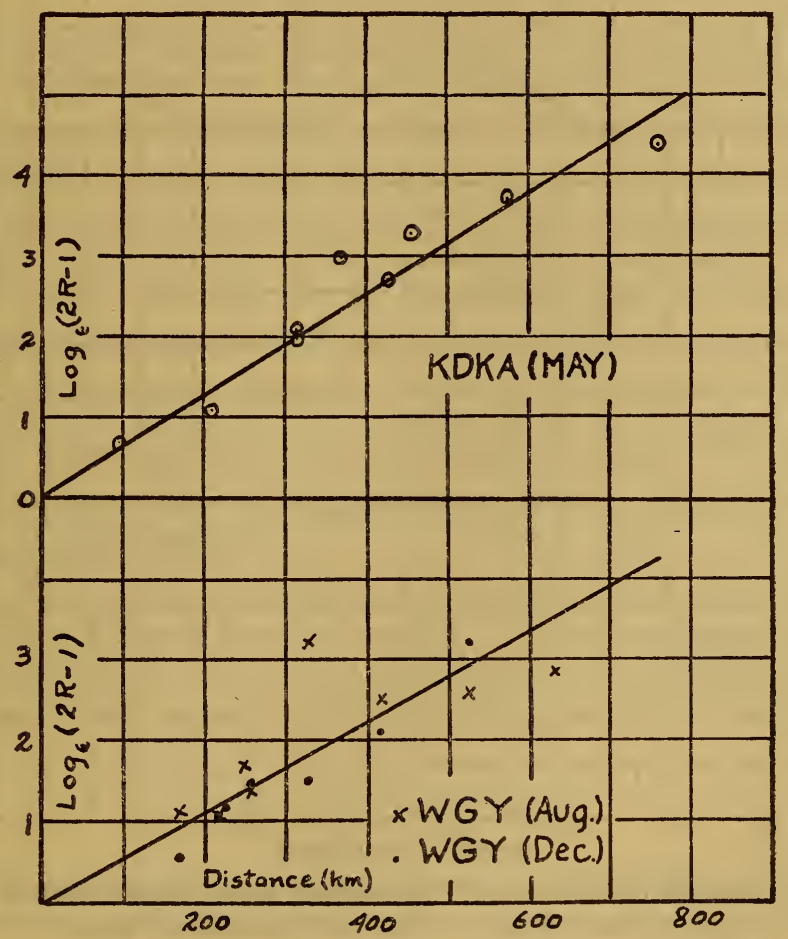

FIG. 18.-Data of Figure 17 replotted with $\log (2 R-1)$ against distance

points for the August and December WGY series lie on the same line. Thus, the average night intensity is definitely related to the distance, independent of time, in spite of the erratic and enormous variation of instantaneous intensity. This result is in harmony with and corroborates the hypothesis ${ }^{19}$ that the night intensity fluctuates between a definite lower and a definite upper limit, the lower being the day intensity and the upper being the value determined by absence of absorption in the transmission path. Assuming that the

10 "Radio signal fading phenomena," J. H. Dellinger and L. E. Whittemore, J. Wash. Acad. Sci., 11, pp. 245-259; June 4, 1921 (see particularly p. 256). "Radio extension of the telephone system to ships at sea," H. W. Nichols and L. Espenschied, Proc. I. R. E., 11, pp. 193-242; June, 1923 (see particularly p. 227). 
intensity fluctuates in entirely random fashion between these two limits, its average value may be taken as $\frac{H_{\mathrm{d}}+H_{\mathrm{o}}}{2}$, where $H_{\mathrm{d}}$ is the lower limit (day intensity) and $H_{0}$ is the upper limit (zero absorption). Now, the day intensity is given by the transmission formula

$$
H_{\mathrm{d}}=H_{0} \epsilon^{-\beta \mathrm{d} \sqrt{\mathrm{I}}}
$$

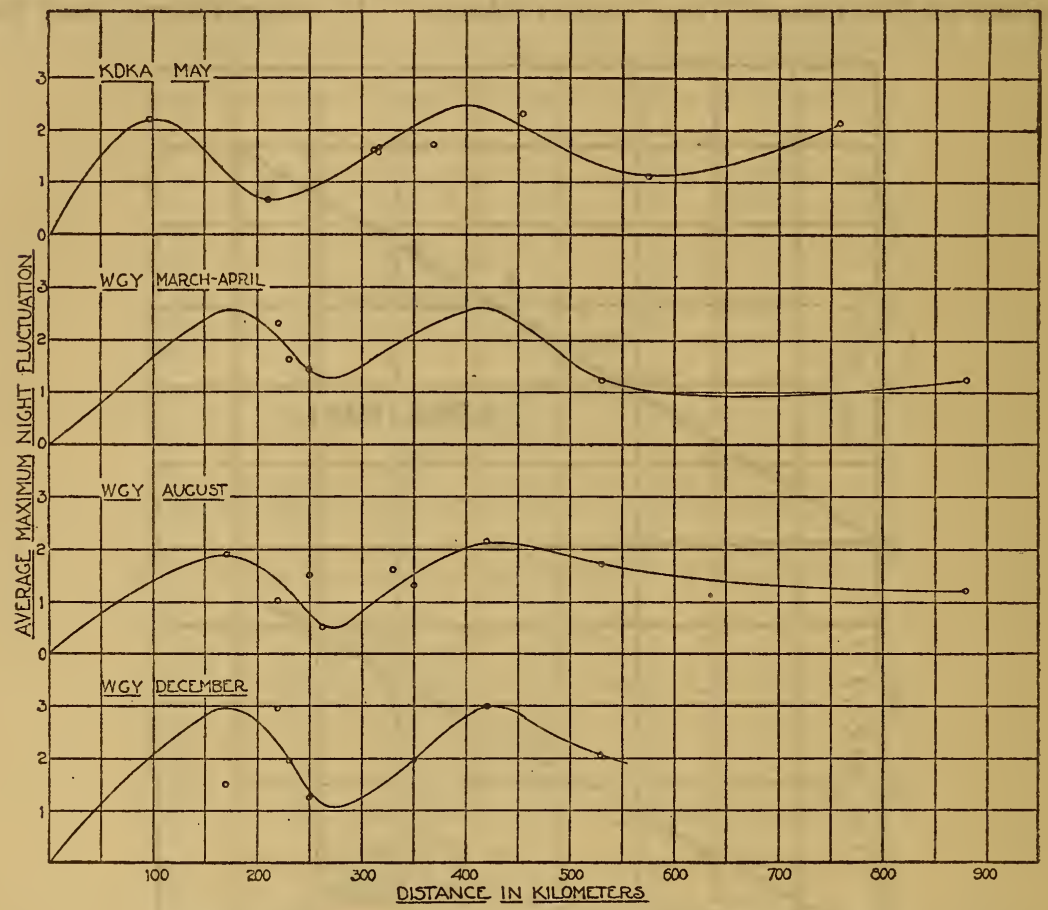

FIG. 19.-Average maximum night fluctuation values plotted against distance from transmitting stations for three series of tests

This formula is equivalent to the original Austin-Cohen formula,

$$
H=H_{0} \epsilon^{-\frac{\alpha d}{\sqrt{\lambda}}}
$$

differing in form in that frequency, in kilocycles, is used instead of wave length in meters. $\beta=0.0058 \alpha$. The ratio of average night intensity to day intensity is therefore

$$
\begin{gathered}
\underline{r}=\frac{H_{\mathrm{d}}+H_{0}}{2 H_{\mathrm{d}}}=\frac{\epsilon^{-\beta \mathrm{d} \sqrt{\mathrm{f}}}+1}{2 \epsilon^{-\beta \mathrm{d} \sqrt{\mathrm{f}}}} \\
(2 r-1)=\epsilon^{\beta \mathrm{d} \sqrt{\mathrm{I}}}
\end{gathered}
$$


This theory thus corroborates the experimentally observed fact that the ratio of night to day average intensity is independent of time. Furthermore, comparison with the graph shows that the relation of this ratio to distance is correctly given by the theory. From the equation just given

$$
\begin{gathered}
\log _{e}(2 r-1)=\beta d \sqrt{f} \\
\log _{10}(2 r-1)=0.434 \beta d \sqrt{f}
\end{gathered}
$$

Figure 18 shows the two graphs plotted with $\log (2 R-1)$ against distance. The value of the absorption coefficient $\beta$, from the slopes of the two straight lines, is 0.0002 . While the points are somewhat scattered, considering the method by which the data were obtained, the agreement of the observed data with the theory is very good. The value of $\beta=0.0002(\alpha=0.003)$ is near the lower limit given by Bown and Gillett ${ }^{20}$ for measurements over land in the vicinity of Washington. ${ }^{20}$ These data would indicate that the value $\beta=0.0002$ is an average for the northeastern part of the United States and that this average is maintained throughout the year. The value for $\alpha$ given by Austin ${ }^{21}$ for sea water is 0.0015 . The March-April tests were not long enough to give sufficient data to be used in a similar analysis.

This result introduces a degree of regularity into fading phenomena which has not hitherto been suspected. The average night intensity for any particular place can apparently be predetermined, even though the intensity varies from instant to instant in wholly erratic fashion.

\section{CONCLUSIONS}

The results of analysis of approximately 150 graphic fading records made by observers in 23 laboratories at various points in northeastern United States and Canada have determined more definitely a number of the previously known characteristics of fading, which are summarized above in Section II, "Status of knowledge of fading." They have, in addition, led to the following conclusions:

1. There is a degree of regularity in the average intensity during conditions of fading which has not hitherto been suspected. The ratio of average night to day intensity has a logarithmic relation to distance. This relation gives quantitative indication that the earth absorption effective in the daytime disappears at times at night and permits calculation of the absorption coefficient.

\footnotetext{
${ }_{20}$ "Distribution of radio waves from broadcasting stations over city districts," Proc. I. R. E., 12, p. 395; August, 1924.

${ }^{21}$ Some Quantitative Experiments in Long-distance Radiotelegraphy. B. S. Sci. Paper No. 159.
} 
2. There is a series of maxima and minima of fluctuation with respect to distance from the transmitting station. The first maximum occurs at about $100 \mathrm{~km}$.

3. The preceding conclusions, taken together with the dying away of the ground-transmitted wave, indicate that the fading of several minutes period is due to variable absorption in the upper atmosphere, and that the fading of several seconds period observed at distances less than about $200 \mathrm{~km}$ is largely due to interference between the ground-transmitted wave and the wave which has traveled to the Kennelly-Heaviside layer and undergone variable changes of intensity, phase, and polarization.

4. There is some evidence of correlation between direction shifts and fast fading. This corroborates the conclusion just stated as to the rôle of interference in producing the fading of several seconds period, since some of the same interference effects would also be manifested as direction shifts.

5. The average of a number of records made on several days at any receiving locality during the sunset period shows a rise in average intensity, starting about an hour before sunset, then (with the exception for north-south transmission noted below) a decrease slightly before or during sunset at the receiving point, and then a rise to a night value, reached usually an hour or two after sunset. This value may not be the night maximum, which may occur many hours later. In case of north-south transmission the limited evidence is that there is no lessening of the rate of increase during the sunset period. All of this is in accordance with a theory advanced by Kennelly and by Nagaoka.

6. There is similarly an increase in the fluctuation, beginning about one hour before sunset, usually with a decrease at or near sunset at the receiving point, and then an increase to a night value, which also fluctuates.

7. Except for the general diurnal correlation just stated, there is no correlation between intensity and fluctuation changes.

8. The maximum diurnal intensity appears at about the same time (during the three hours just preceding sunrise, in December) at all receiving points within $500 \mathrm{~km}$ of the transmitting station. (This conclusion is based on a single 24 -hour observation period.)

9. There is no consistent correlation between fading and weather conditions, as shown on weather maps covering the test periods.

10. There is sometimes a special periodic type of fading, beginning about 15 to 20 minutes after sunset, of great regularity, the periodicity of which shows a correlation with the distance between the transmitting and receiving points, and which is evidently due to an in terference phenomenon. 
11. The effect of a solar eclipse is to produce fading conditions intermediate between those of night and day, similar to sunset conditions.

12. Changes of transmitting power do not affect the characteristics of fading.

\section{ACKNOWLEDGMENTS}

The bureau expresses appreciation to all the institutions and persons who have participated in this cooperative work. Special thanks are due H. S. Shaw, of Newton Center, Mass., who recommended to the bureau the undertaking of a large-scale cooperative program of quantitative measurements of fading. Mr. Shaw not only joined the program as an observer, but also contributed the salary of a research associate to assist the Bureau of Standards to handle the extra work incident to a project of this sort; the funds involved were administered by the American section, International Union of Scientific Radio Telegraphy. Special credit is also due G. W. Pickard, who did the pioneer work of developing methods for making and analyzing quantitative observations of fading; throughout this work he has given freely of his time and has helped by various suggestions. The General Electric Co. station WGY and the Westinghouse Electric \& Manufacturing Co. station KDKA have been most generous in supplying the special transmissions which were essential to the success of the tests. The personnel of the cooperating laboratories have given freely of their time, some of them having made observations on practically every one of the scheduled transmissions. The effort of all of these contributors was essential to the success of the program.

The names of the institutions which cooperated in the observations are listed here. 


\section{Cooperating laboratories}

\begin{tabular}{|c|c|c|c|}
\hline Cooperator & Location & $\begin{array}{c}\text { Distance } \\
\text { from } \\
\text { Sche- } \\
\text { nectady }\end{array}$ & $\begin{array}{l}\text { Distance } \\
\text { from } \\
\text { Pitts- } \\
\text { burgh }\end{array}$ \\
\hline American Telephone \& Telegrap & \{Hohokus, N. J & $\mathrm{km}$ & $\mathrm{km}_{475}$ \\
\hline $\begin{array}{l}\text { Bureau of Standards } \\
\text { Bureau of Standards field station } \\
\text { Clark University }\end{array}$ & $\begin{array}{l}\text { Washington, D, C. } \\
\text { Chevy Chase, Mdd } \\
\text { Worcester, Mass }\end{array}$ & $\begin{array}{r}1,000 \\
530 \\
530 \\
190\end{array}$ & $\begin{array}{l}315 \\
315 \\
600\end{array}$ \\
\hline $\begin{array}{l}\text { Cornell University } \\
\text { Dartmouth College } \\
\text { Dominion Observatory } \\
\text { General Electric Co }\end{array}$ & $\begin{array}{l}\text { Ithaca, N. Y } \\
\text { Hanover, N. H..... } \\
\text { Ottawa, Canada... } \\
\text { Glenville, N. Y..-. }\end{array}$ & $\begin{array}{r}220 \\
170 \\
330 \\
16\end{array}$ & $\begin{array}{l}370 \\
730 \\
665 \\
580\end{array}$ \\
\hline $\begin{array}{l}\text { F. Austin Lidbury } \\
\text { Massachusetts Institute of Technology } \\
\text { Michigan State College } \\
\text { University of Nebraska }\end{array}$ & 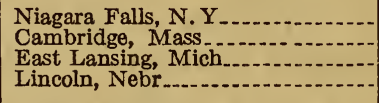 & $\begin{array}{r}420 \\
240 \\
880 \\
1,920\end{array}$ & $\begin{array}{r}315 \\
780 \\
460 \\
1,430\end{array}$ \\
\hline $\begin{array}{l}\text { Oberlin College } \\
\text { University of Pennsylvania } \\
\text { G. W. Pickard } \\
\text { Radio Corporation of America }\end{array}$ & $\begin{array}{l}\text { Oberlin, Ohio } \\
\text { Philadelphia, Pa } \\
\text { Newton Center, Mass. } \\
\text { New York, N. Y............. }\end{array}$ & $\begin{array}{l}715 \\
350 \\
230 \\
250\end{array}$ & $\begin{array}{l}215 \\
425 \\
770 \\
520\end{array}$ \\
\hline $\begin{array}{l}\text { Radio in the home. } \\
\text { H. S. Shaw } \\
\text { Union College }\end{array}$ & 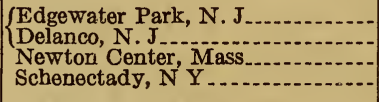 & $\begin{array}{l}350 \\
350 \\
230\end{array}$ & $\begin{array}{l}430 \\
430 \\
770 \\
580\end{array}$ \\
\hline $\begin{array}{l}\text { United States Naval Academy } \\
\text { University of Toronto } \\
\text { West Virginia University } \\
\text { Western Union Telegraph Co } \\
\text { Yalo University }\end{array}$ & $\begin{array}{l}\text { Annapolis, Md } \\
\text { Toronto, Canada } \\
\text { Morgantown, W. Va. } \\
\text { Water Mill, N. Y. } \\
\text { New Haven, Conñ }\end{array}$ & $\begin{array}{l}500 \\
460 \\
625 \\
260 \\
200\end{array}$ & $\begin{array}{r}350 \\
370 \\
97 \\
650 \\
610\end{array}$ \\
\hline
\end{tabular}

Washington, May 27, 1927 